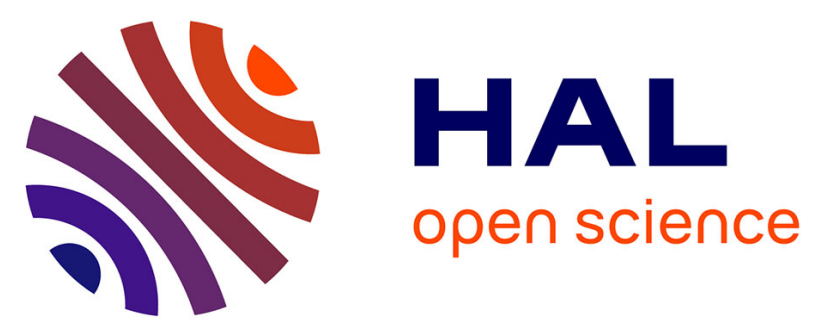

\title{
Weak protein-cationic co-ion interactions addressed by X-ray crystallography and mass spectrometry
}

\author{
Philippe Bénas, Nicolas Auzeil, Laurent Legrand, Franck Brachet, Anne
}

Regazzetti, Madeleine Riès-Kautt

\section{- To cite this version:}

Philippe Bénas, Nicolas Auzeil, Laurent Legrand, Franck Brachet, Anne Regazzetti, et al.. Weak protein-cationic co-ion interactions addressed by X-ray crystallography and mass spectrometry. Acta crystallographica Section D : Structural biology [1993-..], 2014, 70 (8), pp.2217-2231. 10.1107/S1399004714011304 . hal-01120260

\section{HAL Id: hal-01120260 \\ https://hal.sorbonne-universite.fr/hal-01120260}

Submitted on 2 Mar 2015

HAL is a multi-disciplinary open access archive for the deposit and dissemination of scientific research documents, whether they are published or not. The documents may come from teaching and research institutions in France or abroad, or from public or private research centers.
L'archive ouverte pluridisciplinaire HAL, est destinée au dépôt et à la diffusion de documents scientifiques de niveau recherche, publiés ou non, émanant des établissements d'enseignement et de recherche français ou étrangers, des laboratoires publics ou privés. 


\title{
Weak protein-cationic co-ion interactions addressed by X-ray crystallography and mass spectrometry
}

\section{Philippe Bénas, Nicolas Auzeil, Laurent Legrand, Franck Brachet, Anne Regazzetti and Madeleine Riès-Kautt}

Acta Cryst. (2014). D70, 2217-2231

Copyright (C) International Union of Crystallography

Author(s) of this paper may load this reprint on their own web site or institutional repository provided that this cover page is retained. Republication of this article or its storage in electronic databases other than as specified above is not permitted without prior permission in writing from the IUCr.

For further information see http://journals.iucr.org/services/authorrights.html

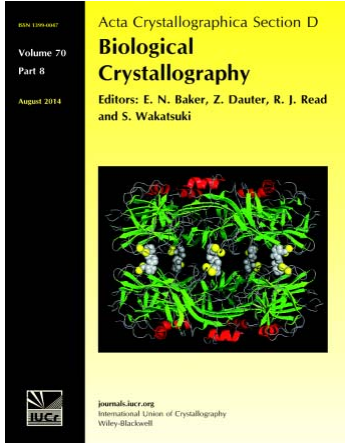

\begin{abstract}
Acta Crystallographica Section D: Biological Crystallography welcomes the submission of papers covering any aspect of structural biology, with a particular emphasis on the structures of biological macromolecules and the methods used to determine them. Reports on new protein structures are particularly encouraged, as are structure-function papers that could include crystallographic binding studies, or structural analysis of mutants or other modified forms of a known protein structure. The key criterion is that such papers should present new insights into biology, chemistry or structure. Papers on crystallographic methods should be oriented towards biological crystallography, and may include new approaches to any aspect of structure determination or analysis. Papers on the crystallization of biological molecules will be accepted providing that these focus on new methods or other features that are of general importance or applicability.
\end{abstract}

Crystallography Journals Online is available from journals.iucr.org 
Acta Crystallographica Section D

Biological

Crystallography

ISSN 1399-0047

Philippe Bénas, ${ }^{\text {a }}$ Nicolas Auzeil, ${ }^{\text {b }}$

Laurent Legrand, ${ }^{\mathrm{c}}$ Franck

Brachet, ${ }^{a}$ Anne Regazzetti ${ }^{\mathrm{b}}$ and Madeleine Riès-Kautt ${ }^{\mathrm{a}} \neq$

aLaboratoire de Cristallographie et RMN Biologiques, Faculté des Sciences

Pharmaceutiques et Biologiques, Université Paris Descartes, UMR 8015 CNRS, 4 Avenue de I'Observatoire, 75270 Paris CEDEX 06, France,

${ }^{b}$ Laboratoire de Chimie-Toxicologie Analytique et Cellulaire EA 4463, Faculté des Sciences Pharmaceutiques et Biologiques, Université Paris Descartes, 4 Avenue de I'Observatoire, 75270 Paris CEDEX 06, France, and ' Institut des NanoSciences de Paris (INSP), UMR 7588 CNRS/UPMC (Université Paris 6), 4 Place Jussieu, 75252 Paris CEDEX 05, France

‡ Present address: 3P5, Institut Cochin, Université Paris Descartes, CNRS (UMR 8104), Inserm U1016, 22 Rue Méchain, 75014 Paris, France.

Correspondence e-mail: madeleine.ries@inserm.fr

\section{Weak protein-cationic co-ion interactions addressed by $\mathrm{X}$-ray crystallography and mass spectrometry}

The adsorption of $\mathrm{Rb}^{+}, \mathrm{Cs}^{+}, \mathrm{Mn}^{2+}, \mathrm{Co}^{2+}$ and $\mathrm{Yb}^{3+}$ onto the positively charged hen egg-white lysozyme (HEWL) has been investigated by solving $13 \mathrm{X}$-ray structures of HEWL crystallized with their chlorides and by applying electrospray ionization mass spectrometry (ESI-MS) first to dissolved protein crystals and then to the protein in buffered salt solutions. The number of bound cations follows the order $\mathrm{Cs}^{+}<\mathrm{Mn}^{2+} \simeq \mathrm{Co}^{2+}<\mathrm{Yb}^{3+}$ at $293 \mathrm{~K}$. HEWL binds less $\mathrm{Rb}^{+}$ $\left(q_{\mathrm{tot}}=0.7\right)$ than $\mathrm{Cs}^{+}\left(q_{\mathrm{tot}}=3.9\right)$ at $100 \mathrm{~K}$. Crystal flash-cooling drastically increases the binding of $\mathrm{Cs}^{+}$, but poorly affects that of $\mathrm{Yb}^{3+}$, suggesting different interactions. The addition of glycerol increases the number of bound $\mathrm{Yb}^{3+}$ cations, but only slightly increases that of $\mathrm{Rb}^{+}$. HEWL titrations with the same chlorides, followed by ESI-MS analysis, show that only about $10 \%$ of HEWL binds $\mathrm{Cs}^{+}$and about $40 \%$ binds $1-2 \mathrm{Yb}^{3+}$ cations, while the highest binding reaches $60-70 \%$ for protein binding $1-3 \mathrm{Mn}^{2+}$ or $\mathrm{Co}^{2+}$ cations. The binding sites identified by X-ray crystallography show that the monovalent $\mathrm{Rb}^{+}$ and $\mathrm{Cs}^{+}$preferentially bind to carbonyl groups, whereas the multivalent $\mathrm{Mn}^{2+}, \mathrm{Co}^{2+}$ and $\mathrm{Yb}^{3+}$ interact with carboxylic groups. This work elucidates the basis of the effect of the Hofmeister cation series on protein solubility.

\section{Introduction}

Studies in physical chemistry have shown that ions affect a large number of the properties of salt solutions (Collins \& Washabaugh, 1985) according to the Hofmeister series (Hofmeister, 1888; Kunz et al., 2004), including protein solubility, macromolecular conformations (Von Hippel \& Schleich, 1969) and more generally protein-protein interactions in solution. Ion-specific effects have been attributed to their ability to structure water molecules, giving rise to the classification of ions as chaotropes and kosmotropes. The former are those that disrupt the water network, or 'structure breakers', such as $\mathrm{K}^{+}, \mathrm{Cs}^{+}, \mathrm{NH}_{4}^{+}, \mathrm{SCN}^{-}$and $\mathrm{I}^{-}$, whereas the latter, such as $\mathrm{SO}_{4}^{2-}, \mathrm{HPO}_{4}^{2-}, \mathrm{Mg}^{2+}$ and $\mathrm{Li}^{+}$, are called 'structure makers' and are able to reorder water molecules around themselves.

As far as protein solubility and crystallization are concerned, the question was whether the salts act indirectly by structuring or perturbing the protein hydration shell or directly as ion pairs with ionic sites on the protein surface. Indeed, for a long time the salt effect was attributed to perturbation of the protein hydration shell (Tanford, 1961; Arakawa \& Timasheff, 1984) by salts competing for their own hydration, before direct interactions of bulk solution ions with charged groups at the surface of the protein were considered
Received 20 February 2014 Accepted 15 May 2014

PDB references: HEWL in $0.5 \mathrm{M} \mathrm{MnCl}_{2}$, data collected at room temperature, 4 neb; HEWL in $1.1 \mathrm{M} \mathrm{MnCl}_{2}$, data collected at room temperature, $4 \mathrm{nfv}$; HEWL in $1.9 \mathrm{M}$ $\mathrm{CsCl}$, data collected at room temperature, 4ng1; dialyzed HEWL batch-crystallized in $1.9 \mathrm{M} \mathrm{CsCl}$, data collected at $100 \mathrm{~K}, 4$ ng8; previously deionized HEWL crystallized in $1.0 \mathrm{M} \mathrm{RbCl}$, data collected at 125 K, 4ngi; dialyzed HEWL batch-crystallized in $1.0 \mathrm{M}$ $\mathrm{RbCl}$, data collected at $100 \mathrm{~K}$, $4 \mathrm{ngj}$; previously deionized HEWL batch-crystallized in $0.2 \mathrm{M} \mathrm{CoCl}_{2}$, 4ngk; previously deionized HEWL batch-crystallized in $1.0 \mathrm{M}$ $\mathrm{CoCl}_{2}$, 4ngo; previously deionized HEWL batchcrystallized in $0.6 \mathrm{M} \mathrm{CoCl}_{2}$, $4 \mathrm{ngl}$; previously deionized HEWL batch-crystallized in $0.5 \mathrm{M} \mathrm{YbCl}_{3}$, 4ngv; dialyzed HEWL batch-crystallized in $0.5 \mathrm{M} \mathrm{YbCl}_{3}$, data collected at $100 \mathrm{~K}, 4 \mathrm{ngw}$; dialyzed HEWL batch-crystallized in $0.75 \mathrm{M}$ $\mathrm{YbCl}_{3}$, data collected at $100 \mathrm{~K}, 4$ ngy; previously deionized HEWL crystallized in $0.48 \mathrm{M} \mathrm{YbCl}_{3} / 30 \%(\mathrm{v} / \mathrm{v})$ glycerol, data collected at $125 \mathrm{~K}, 4 \mathrm{ngz}$ 
to form ion pairs (Riès-Kautt \& Ducruix, 1997; Collins, 2006; Zhang \& Cremer, 2006). Ion pairing further relies on a concept according to which ions are more likely to bind to each other according to the law of matching water affinity (Collins \& Washabaugh, 1985; Washabaugh \& Collins, 1986) or the hard/soft concept (Pearson, 1987). The identification of the nature of these pairs gives access to new tools that are able to be generalized for protein crystallization. Reviews of the effects of ionic strength on ion-protein interactions have underlined the importance of their chemistry (Collins, 2012).

We have already revisited the effect of anions in previous solubility studies (Riès-Kautt \& Ducruix, 1989) and crystallographic analyses (Vaney et al., 2001) of the positively charged hen egg-white lysozyme (HEWL). This led us to demonstrate that anions directly interact as counter-ions with the protein surface of HEWL and are responsible for the observed solubility decrease when increasing the salt concentration and mostly when changing the nature of the anion (Riès-Kautt \& Ducruix, 1997) from acetate to thiocyanate. This observation could be confirmed for the crystallization of other positively charged proteins, such as BPTI (Hamiaux et al., 1999) and toxins (Ménez \& Ducruix, 1990, 1993; Saludjian et al., 1992).

We have shown that the adsorption of counter-ions decreases the effective protein net charge and consequently the protein solubility in aqueous salt solutions (Riès-Kautt \& Ducruix, 1991). The effectiveness of the investigated anions appears to follow the reverse of Hofmeister's series, which is linked to the better affinity of soft ions to interact with positively charged sites of the protein. Conversely, we suggested that the adsorption of co-ions, if it occurs, should increase the apparent net charge of the protein and hence its solubility. We effectively measured such a behaviour for the positively charged HEWL crystallized in the presence of several monovalent, divalent and trivalent cation chlorides and observed a solubility increase when lysozyme was crystallized with multivalent cations (Bénas et al., 2002). Results published for $\mathrm{HEWL}$ crystallized with $\mathrm{NiCl}_{2}$ (Li et al., 2005) also showed increased solubility of this protein above $0.5 \mathrm{M}$. In the literature, however, these effects have been better documented for anions than for cations. Among the latter, monovalent cations have been more investigated than multivalent cations, as in Hofmeister's original work.

It must be emphasized that this work does not address the binding of cations with high association constants that have a structural or catalytic function in proteins, since lysozyme does not require any cations for its catalytic activity. We deal here with cations interacting as co-ions with solvent-exposed sites of protein surfaces in general. Such weak interactions are more difficult to characterize than are strong biochemical associations. We therefore undertook a further investigation of cation adsorption using two very different but complementary biophysical approaches: X-ray crystallography and mass spectrometry. We aimed to define a possible stoichiometry for cations bound to HEWL by these two approaches, possibly estimating the relative abundance of the free protein and the HEWL-cation complexes, and eventually to describe their binding sites.
Crystallographic structure determination allows ions or molecules adsorbed onto protein molecules to be observed depending on their occupancy factor $q$. The latter is the fraction of the asymmetric units in the irradiated crystal volume in which they are present at a given position and averaged over the data-collection time. In this approach the thermal agitation factor $B$ is another important and correlated parameter in assigning solvent molecules. In the present study we also have performed careful data processing and analysis as well as precise calculations (Weiss et al., 2002) in order to overcome the difficulty in discriminating between ions and water molecules. Furthermore, the anomalous signal contribution of the studied cations has been taken into account as described by Dauter and Dauter for anions bound to HEWL (Dauter \& Dauter, 1999). The best possible electron-density assignments for the solvent molecules were finally obtained in conjunction with a careful analysis of the chemical environment.

Electrospray ionization mass spectrometry (ESI-MS) has also proven to be an approach for revealing noncovalent binding, including metal ions binding to proteins as reviewed by Potier et al. (2005). As early as 1994, we observed the adsorption of sulfate and phosphate onto lysozyme when studying the effect of anions on protein solubility (Riès-Kautt et al., 1994). This has also been applied to demonstrate that HEWL can bind up to six $\mathrm{Zn}^{2+}$ or eight $\mathrm{Cu}^{2+}$ cations in water at pH 6.9 (Moreau et al., 1995).

ESI-MS can identify ions that have too low an occupancy or too high a temperature factor and hence are hidden in the bulk solvent in X-ray structures. However, it cannot provide information either about their location on the protein or about ions trapped at protein interfaces owing to crystal packing. Nevertheless, cation interactions occurring at high ionic strength during HEWL crystallization cannot be directly investigated by ESI-MS analysis, since the high salt content hampers the ionization process. We have therefore tested two different ESI-MS analysis approaches. In the first series, crystals from the same crystallization batches as used for the $\mathrm{X}$-ray and solubility studies were dissolved in water-MeOH [85:15(v:v)]. In the second series, a diluted HEWL solution was titrated with increasing concentrations of $\mathrm{Cs}^{+}, \mathrm{Mn}^{2+}, \mathrm{Co}^{2+}$ and $\mathrm{Yb}^{3+}$ chlorides.

The two combined ESI-MS approaches are compared with the crystallographic results to provide insights into the stoichiometry of HEWL complexes with cations as well as the relative efficiency of cation binding to HEWL.

\section{Materials and methods}

\subsection{Reagents and solution preparations}

HEWL (Sigma catalogue No. L6876, batch 73H7045) was desalted to its isoionic state, i.e. with the only possible counterions being $\mathrm{H}^{+}$and $\mathrm{OH}^{-}$, as previously detailed in Retailleau, Ducruix et al. (1997). The isoionic protein solution was then acidified to $\mathrm{pH} 4.5$ by the addition of about ten molar equivalents of $\mathrm{HCl}$, allowing all cations to be tested as chloride 
salts. The purity of the HEWL was checked by SDS-PAGE followed by enhanced silver staining (Thomas et al., 1996), showing a single band, and by ESI-MS $\left(M_{\mathrm{r}}=14305 \pm 2\right)$. The crystals used for data collection at $100 \mathrm{~K}$ were grown using HEWL (Fluka Analytical 62971-50G-F, batch 0001356468) without further purification.

Commercial deionized and thrice-distilled water (Meram, France) was used to prepare the solutions. All chloride salts were of ACS grade with purity greater than $99 \%$. $\mathrm{CsCl}$ was purchased from Bethesda Research Laboratory (Maryland, USA), $\mathrm{RbCl}$ and $\mathrm{YbCl}_{3} \cdot 6 \mathrm{H}_{2} \mathrm{O}$ from Aldrich, $\mathrm{MnCl}_{2} \cdot 4 \mathrm{H}_{2} \mathrm{O}$ and $\mathrm{CoCl}_{2} \cdot 6 \mathrm{H}_{2} \mathrm{O}$ from Merck and ammonium acetate from Fluka (Saint-Quentin Fallavier, France). AP Normapur glycerol (VWR) was used at a purity of $\geq 99.5 \%$.

All salt stock solutions were filtered through $0.22 \mu \mathrm{m}$ filter systems (Polylabo 22676, Nalgene 90621) and their concentrations were checked by measurement of the refractive index. Glycerol stock solutions were filtered through $0.45 \mu \mathrm{m}$ Polylabo-Nalgene filter units.

Lysozyme was filtered through a $0.22 \mu \mathrm{m}$ Millipore filter (Millex-GV4). The protein concentration was determined by UV absorption at $280 \mathrm{~nm}$, using $\varepsilon_{0.1 \%}=2.66 \mathrm{~g} \mathrm{~g}^{-1} \mathrm{~cm}^{-1}$, and was averaged from two or three measurements falling within $10 \%$ accuracy.

HEWL $(2 \mu M)$ solutions for the ESI-MS titration experiments were prepared in $20 \mathrm{mM}$ ammonium acetate buffer adjusted to $\mathrm{pH} 4.5$ with diluted $\mathrm{HCl}$. Cation solutions (20$600 \mu M$ final salt concentration) were mixed with HEWL and stored at $20^{\circ} \mathrm{C}$ for $30 \mathrm{~min}$ before analysis.

\subsection{HEWL crystallization in cation chloride solutions}

Crystallization conditions are summarized in Table 1. The $\mathrm{pH}$ of crystallizing drops was checked to be $4.5 \pm 0.1$ using a micro-electrode. No buffer was added in order to limit investigations to the effect of chlorides and the given cations under study. All crystallizations were performed at $18 \pm 0.1^{\circ} \mathrm{C}$ in a thermally regulated incubator.

All batch crystallizations were set up using the microbatch method in order to ensure the actual salt and protein concentrations. For convenience of crystal mounting in capillaries, $10 \mu \mathrm{l}$ microbatches were set up as sitting drops (Emerald Bio crystallization plates) over a well containing the same salt-solution concentration as that within the crystallization drops.

Crystal growth in the presence of glycerol was performed in $9+9 \mu \mathrm{l}$ sitting drops by vapour diffusion. The salt and protein concentrations indicated in Table 1 are those expected at equilibrium, i.e. twice the known initial concentration.

\subsection{Crystallography}

2.3.1. X-ray data collection and processing. One single crystal was used for each data collection and details can be found in Table 1. All but the X-ray data collected at $100 \mathrm{~K}$ were processed using programs from the $H K L$ package v.1.96.2. X-ray diffraction patterns were indexed and inte- grated using $D E N Z O$ and the data were further reduced using SCALEPACK (Otwinowski \& Minor, 1997). The data collected at $100 \mathrm{~K}$ were indexed, integrated and reduced using the XDS package (Kabsch, 2010a,b). Friedel's law was assumed to be false in the data-reduction step.

The reduced reflection files were converted to MTZ format using SCALEPACK2MTZ from the CCP4 suite (Winn et al., 2011) or using $X D S C O N V$ from the $X D S$ package and were then brought to an absolute scale using the $C C P 4$ program TRUNCATE (French \& Wilson, 1978).

As shown in Table 1, the overall statistics are satisfactory. The value of $86 \%$ for the completeness of the $4 \mathrm{ngl}$ data set is explained by a data collection that was limited to $90^{\circ}$ while the crystal orientation would have required a total rotation angle of $160^{\circ}$.

2.3.2. Crystal structure refinement and manual rebuilding. The crystal structures were solved by straightforward molecular replacement using the polypeptide chain of PDB entry 1931 (Vaney et al., 1996) as an initial model. Molecular replacement for crystals at room temperature or at $125 \mathrm{~K}$ was conducted with $A M o R e$ (Navaza, 1994) and the structures of crystals at $100 \mathrm{~K}$ were solved by Phaser (McCoy et al., 2007). For all of the anomalous data sets, a total of seven iterative cycles of structure refinement using CNS (Crystallography and NMR System) v.1.1 (Brünger et al., 1998) and manual rebuilding in either $O$ (v.7.0.1 or 8.2; Jones et al., 1991) or Coot (Emsley et al., 2010) were performed. CNS refinements were based on structure-factor amplitudes (as a cross-validated data set by free $R$ flags) and maximum-likelihood target functions. The bulk-solvent $B$ factor was assumed to be anisotropic in the refinement cycles. Briefly, each $C N S$ cycle consisted of the following: file generation (atomic coordinates and structure file) and optimization of the X-ray versus geometry weights followed by simulated-annealing molecular dynamics on torsion angles and then individual $B$-factor refinement. Alternate conformation occupancies of the protein were then refined along with the occupancies of the solvent molecules, namely protein-bound ions and water molecules. Electrondensity maps (both standard and $\sigma_{\mathrm{A}}$-weighted; Read, 1986) were generated using the calculated phases from the output model.

A final refinement cycle was performed with up-to-date refinement software (REFMAC v.5.8) from the CCP4 suite using the efficient refinement and automated rebuilding programs available on the $P D B_{-} R E D O$ web server (Joosten $e t$ al., 2011).

The usual statistics of crystallographic refinement and geometrical parameters were monitored (see Table 2).

2.3.3. Electron-density inspection and atom discrimination. Water molecules, cations and chlorides were placed in the electron-density maps based on several criteria. The first was the size of the electron-density blobs to be filled in, for instance if the identification of well defined metal sites is easy according to their large number of electrons. The situation becomes less evident at low occupancies and with overlapping binding sites, so that confusion with chlorides or water molecules may possibly occur. Peak heights have therefore been 
Table 1

Crystallization conditions and data-collection statistics.

Values in parentheses are for the outermost shell.

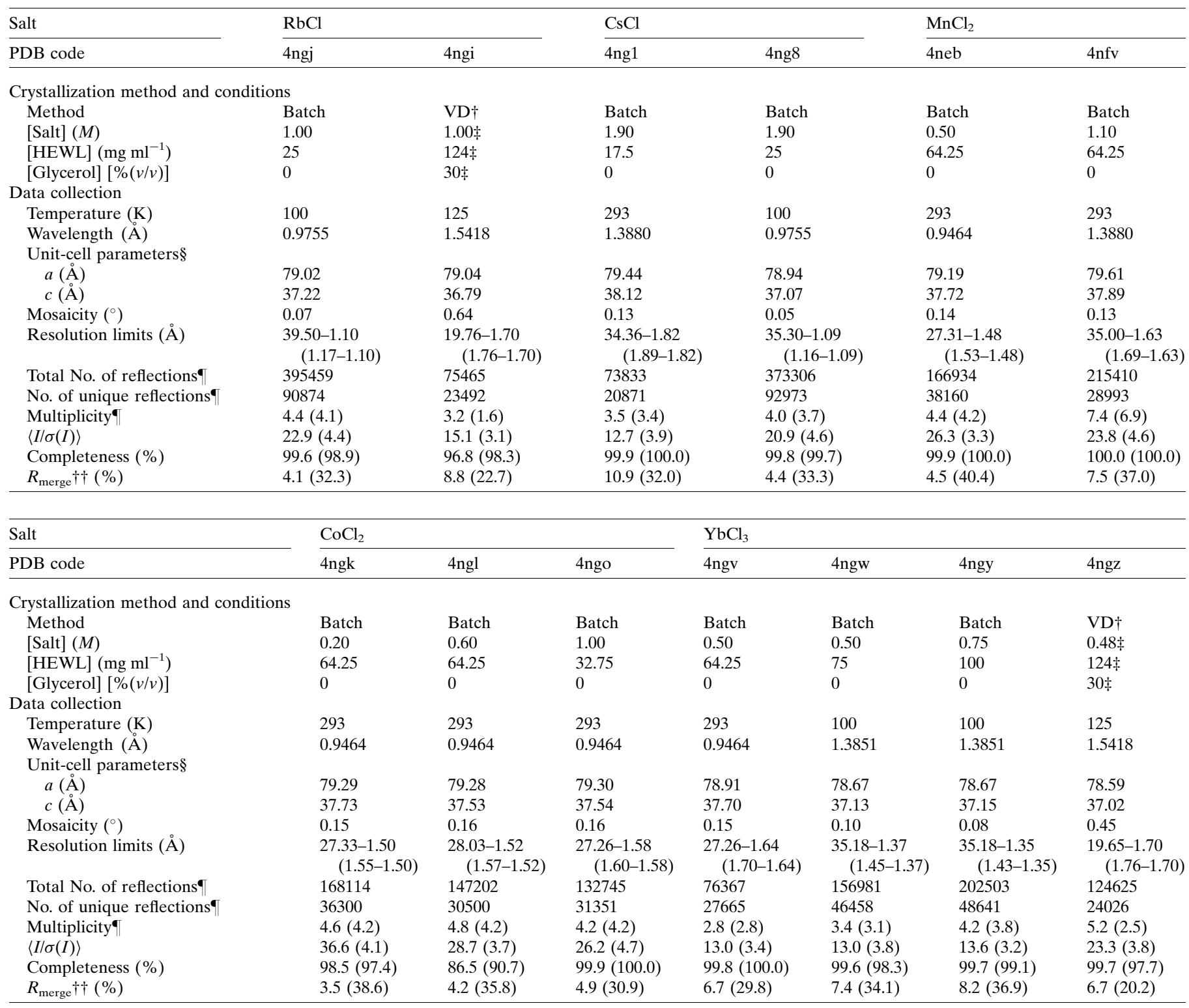

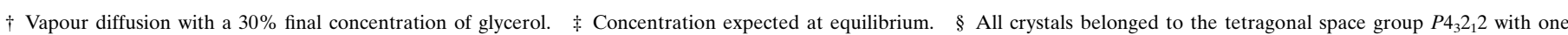
molecule per asymmetric unit. - C Considering all the anomalous pairs $F^{+}$and $F^{-}$. $\dagger \dagger R_{\text {merge }}=\sum_{h k l} \sum_{i}\left|I_{i}(h k l)-\langle I(h k l)\rangle\right| / \sum_{h k l} \sum_{i} I_{i}(h k l)$.

compared using the sulfur peaks of cysteine as internal standards following the method proposed by Weiss et al. (2002). Theoretical electron-density maps have similarly been computed including either the investigated ion or a water molecule. Further occupancy and temperature-factor refinements using one or the other of the models have nevertheless shown that the method remains indicative owing to the strong correlation between occupancies and temperature factors. The proper identification was then based on either the presence or absence of an anomalous signal in the corresponding Bijvoet difference Fourier maps on one hand and the chemical environment of the electron-density blob to be attributed on the other. The divalent and trivalent cations studied in this work have rather short binding distances and hence are quite easily assigned in electron-density maps, although use of the anomalous signal was required for the proper assignment of alternate positions at site $\mathrm{A} 1$ for $\mathrm{Mn}^{2+}$ and $\mathrm{Yb}^{3+}$. In contrast, $\mathrm{Cs}^{+}$ions $(Z=55)$ have binding distances that cover the range of hydrogen bonds up to $3.85 \AA$, but a low occupancy correlated with a high thermal agitation can blur proper identification. Assignments were therefore greatly helped by the electron-density peaks found in the Bijvoet difference Fourier maps, despite the large number of $\mathrm{Cs}^{+}$electrons. $\mathrm{Rb}^{+}$ions have binding distance lengths comparable to hydrogen bonds and interact with atoms bearing lone-pair electrons as hydrogen would. They are thus very hard to detect assuming Friedel's law to be true, i.e. neglecting their anomalous contribution to the observed structure factors. 
Table 2

Refinement statistics.

Values in parentheses are for the outermost shell.

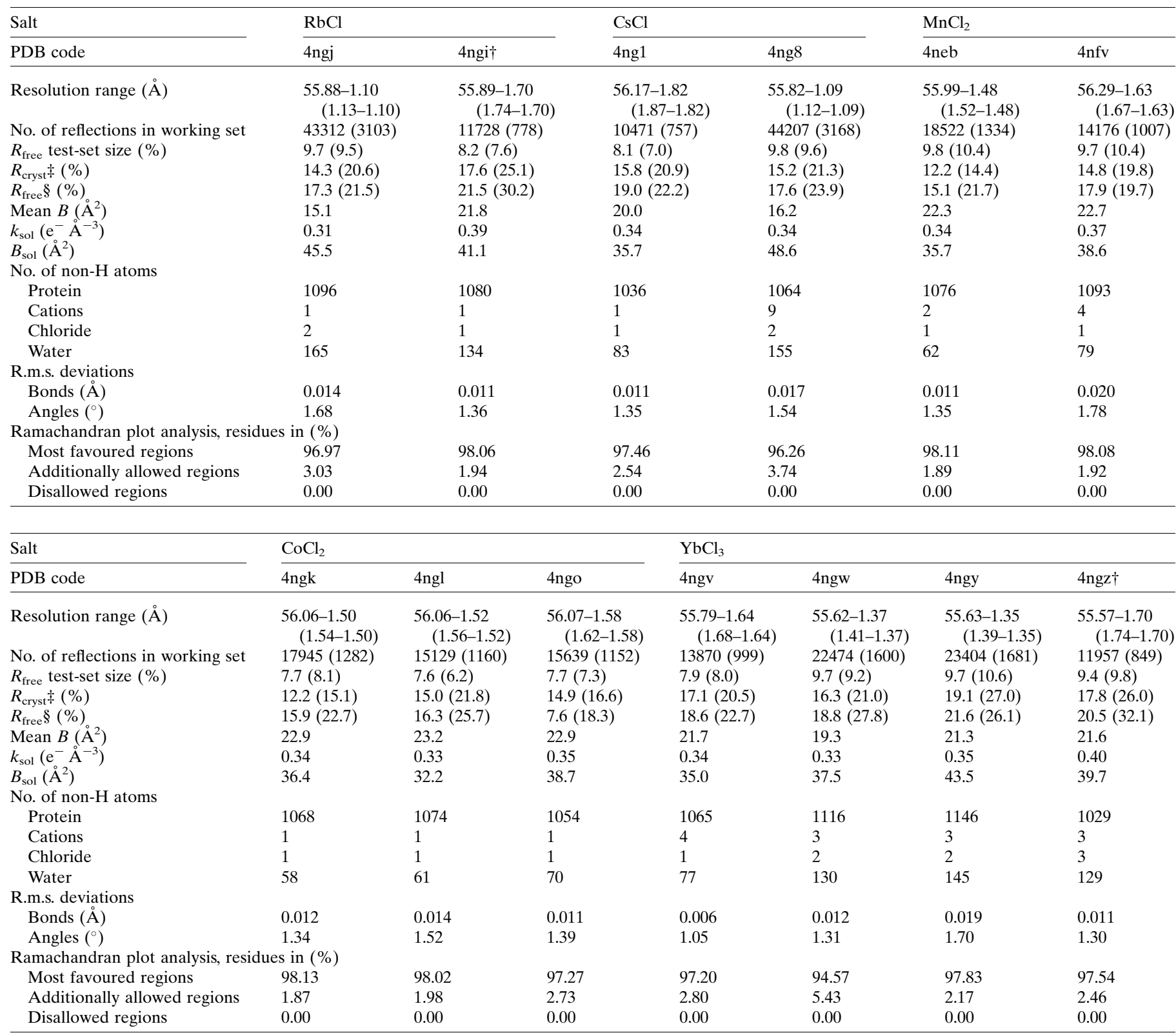

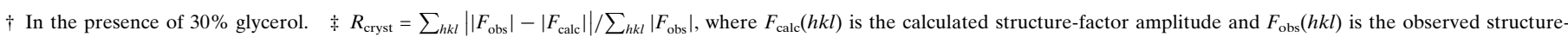
factor amplitude. $\S R_{\text {free }}$ is calculated as $R_{\text {cryst }}$, where the $F_{\text {obs }}$ are taken from a test set that were excluded from the refinement (the size of the test set given in the table).

Depending on the incident wavelength, the anomalous dispersive contribution and the corresponding $f^{\prime \prime}$ can be as low as $0.46 \%$ and $0.22 \mathrm{e}^{-}$for $\mathrm{S}$ atoms and $0.19 \%$ and $0.28 \mathrm{e}^{-}$for chloride ions, respectively. Nevertheless, in all crystal structures reported here the anomalous signal was clearly visible in the electron-density maps for each $\mathrm{S}$ and $\mathrm{Cl}$ atom, and in particular for the disulfide bridges and the well characterized $\mathrm{Cl}^{-}$bound to the $\mathrm{OH}$ group of Tyr23. As for cations, the lowest dispersive contribution is always higher than $1 \%$ and the lowest expected $f^{\prime \prime}\left(1.23 \mathrm{e}^{-}\right)$found for the $\mathrm{MnCl}_{2} / \mathrm{HEWL}$ crystal collected at a radiation wavelength of $0.94 \AA$ is still more than five times larger than the lowest $f^{\prime \prime}$ expected for the $\mathrm{S}$ atoms. After data processing to include the anomalous contributions we were hence able to unambiguously assign the ions bound to the protein by comparing the observed anomalous signal for the $\mathrm{S}$ atoms and the Tyr23-bound $\mathrm{Cl}^{-}$with those at other locations and by evaluating their chemical environment.

Fig. 2 was prepared using PyMOL (Schrödinger) and Figs. 8-11 using Discovery 4 (Discovery Studio Modeling Environment, Release 4.0, Accelrys Software Inc., San Diego, USA). 


\subsection{Mass spectrometry}

ESI-MS analyses were performed with an ion-trap mass spectrometer working in positive-ion mode (Thermo Fisher Scientific, France). The Xcalibur (Thermo Fisher Scientific) software was used for data acquisition and analysis. The voltage of the spray needle was set to $4.0 \mathrm{kV}$, that of the electrospray capillary was $46 \mathrm{~V}$ and that of the tube lens offset was $46 \mathrm{~V}$, and the capillary temperature was $200^{\circ} \mathrm{C}$. The spray was stabilized with nitrogen as the sheath gas (60 arbitrary units) and auxiliary gas (20 arbitrary units). These optimized parameters gave the best sensitivity without disrupting noncovalent interactions in the gas phase. The syringe-pump flow rate was set to $5 \mu \mathrm{min}^{-1}$. The acquisition time was fixed at $1 \mathrm{~min}$. Three micro-scans were collected to produce a unique scan and the duration of the accumulation of ions in the analyser was $50 \mathrm{~ms}$. Acquisition was performed in full scan mode between $\mathrm{m} / \mathrm{z} 200$ and 2000 and mass spectra were acquired and displayed in a profile data type. After each acquisition, a Surveyor HPLC pump (Thermo Fisher Scientific) was used to wash the acquisition system with water at a flow rate of $200 \mu \mathrm{l} \mathrm{min}^{-1}$ for $20 \mathrm{~min}$. The BioWorks Browser software (v.3.0; Thermo Fisher Scientific) was used to calculate an average mass by deconvolution for free HEWL and for HEWL-cation complexes.

Crystals grown in the same series of experiments as those used for X-ray diffraction were dissolved in $200 \mu \mathrm{l} \mathrm{H}_{2} \mathrm{O}$ prior to analysis.

The second series of experiments were run with HEWL solutions in ammonium acetate, i.e. not from dissolved crystals. After each run containing a cation chloride salt, a spectrum was acquired for a $2 \mu M$ HEWL solution made with $20 \mathrm{mM}$ ammonium acetate buffer as the sole component in order to verify the complete disappearance of HEWL-ion adducts. Before the next acquisition the system was finally washed with water at a flow rate of $200 \mu \mathrm{min}^{-1}$ for a further $20 \mathrm{~min}$. For each solution, mass spectra were acquired three times.

Several assumptions were used and have to be reported to specify the validity range for quantitative analysis in titration experiments. It is assumed that the signal response for each

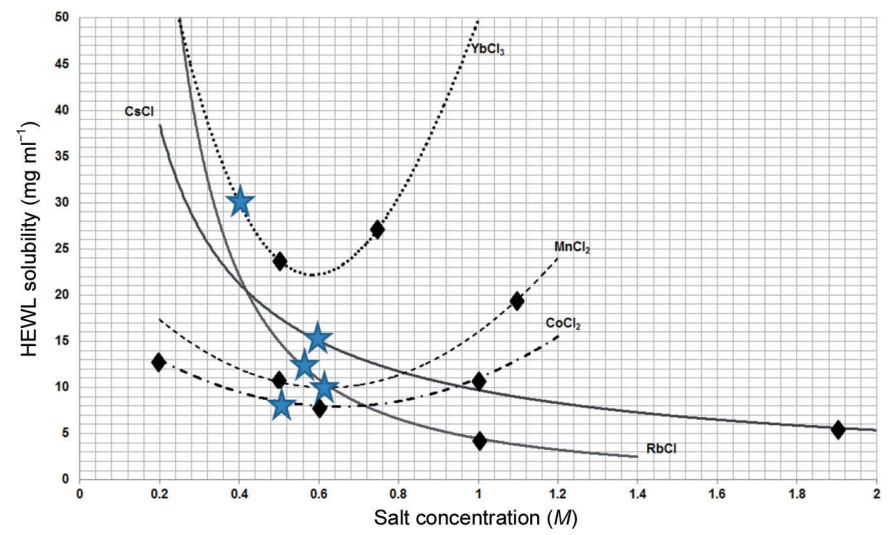

Figure 1

Indication of the crystals used for X-ray diffraction (diamonds) and for ESI-MS (stars) experiments on the HEWL solubility curves ( $\mathrm{pH} 4.5$ and $\left.25^{\circ} \mathrm{C}\right)$. individual species is proportional to its concentration in the gas phase and, by inference, in solution (Whittal et al., 2000). It is also anticipated that free and cation-bound proteins give the same signal response. It seems reasonable to consider that cation binding does not drastically affect the protein conformation since the shape and the charge-state distribution for free and cation-bound HEWL are identical. Thus, it was assumed that both free HEWL and HEWL in complex with cations had equivalent desorption and ionization behaviours. Consequently, the various HEWL species recorded differ only by mass increments corresponding to the binding of ions. Under this assumption, the relative ion abundances recorded for the free and complexed HEWL are considered to be a direct measurement of their relative concentrations in solution.

\section{Results and discussion}

The HEWL crystals used for the X-ray diffraction and ESI-MS experiments (diamonds and stars, respectively, in Fig. 1) were selected from crystallization experiments aimed at determining the solubility curves (Bénas et al., 2002).

For the X-ray crystal analysis, a single crystal with good diffraction properties was chosen for each type of cation from batches corresponding to the decreasing part of the HEWL solubility curves. Further HEWL structures have been determined at higher $\mathrm{MnCl}_{2}, \mathrm{CoCl}_{2}$ and $\mathrm{YbCl}_{3}$ concentrations where the solubility increases in order to find a possible explanation for the particular solubility behaviour observed with the multivalent cations.

All crystals belonged to the tetragonal space group $P 4_{3} 2_{1} 2$ (see Table 1 for data-collection statistics) and the protein structures are almost identical: the average root-mean-square deviation for the coordinates (〈r.s.m.d. $\rangle$ ) is $0.19 \pm 0.09 \AA$ considering the protein main-chain atoms and $0.63 \pm 0.14 \AA$ considering all protein atoms.

The crystals for the ESI-MS measurements were chosen at the highest salt concentration compatible with the technique and as close as possible to the conditions of the crystals for $\mathrm{X}$-ray diffraction.

\subsection{Types and numbers of ions identified by X-ray crystallography}

Table 3 summarizes the nature and the numbers of ions identified by X-ray crystallography along with the corresponding crystallization and data-collection conditions. The total number of ions, $q_{\text {tot }}$, is the sum of the individual $q$ values over all sites where the ion is observed in a given structure. The details of the binding sites and the chemical environment are further discussed in $\S 3.3$.

3.1.1. Data collected at room temperature. The number of bound cations in the structures corresponding to the decrease in solubility with increasing salt concentration follows the order $\mathrm{Cs}^{+}<\mathrm{Co}^{2+} \simeq \mathrm{Mn}^{2+}<\mathrm{Yb}^{3+}$. Only one binding site (site E) is observed for $\mathrm{Cs}^{+}$. It binds with an occupancy of 0.23 , although the crystal was grown in $1.9 \mathrm{M} \mathrm{CsCl}$. The multivalent 
Table 3

Numbers of ions identified in the HEWL structures.

\begin{tabular}{|c|c|c|c|c|c|c|c|c|c|c|c|c|c|}
\hline \multirow{2}{*}{$\frac{\text { Salt }}{\text { PDB code }}$} & \multicolumn{2}{|c|}{$\mathrm{RbCl}$} & \multicolumn{2}{|l|}{$\mathrm{CsCl}$} & \multicolumn{2}{|c|}{$\mathrm{MnCl}_{2}$} & \multicolumn{3}{|c|}{$\mathrm{CoCl}_{2}$} & \multicolumn{4}{|c|}{$\mathrm{YbCl}_{3}$} \\
\hline & $4 \mathrm{ngj}$ & 4ngi† & 4ng1 & 4ng8 & 4neb & $4 n f v$ & 4 ngk & $4 n g l$ & 4ngo & 4 ngv & $4 \mathrm{ngw}$ & 4ngy & 4ngz $\dagger$ \\
\hline$[$ Salt $](M)$ & 1.00 & 1.00 & 1.90 & 1.90 & 0.50 & 1.10 & 0.20 & 0.60 & 1.00 & 0.50 & 0.50 & 0.75 & 0.48 \\
\hline Data-collection temperature (K) & 100 & 125 & 293 & 100 & 293 & 293 & 293 & 293 & 293 & 293 & 100 & 100 & 125 \\
\hline All cations $q_{\text {total }}$ & 0.72 & 0.76 & 0.23 & 3.90 & $\mathbf{0 . 8 0}$ & 1.33 & 0.54 & 0.83 & $\mathbf{0 . 8 0}$ & 1.38 & 1.51 & 1.89 & 1.92 \\
\hline \multicolumn{14}{|l|}{ Sites A } \\
\hline \multirow[t]{2}{*}{ A1 (Asp52) } & & & & 0.28 & 0.31 & $\begin{array}{l}0.30 \\
0.34\end{array}$ & 0.54 & 0.83 & 0.80 & 0.67 & 0.55 & 0.75 & 0.79 \\
\hline & & & & & & 0.24 & & & & 0.22 & & & \\
\hline A2 (Glu35) & & & & & 0.49 & 0.45 & & & & 0.10 & & & \\
\hline A3 (Asn46) & & & & $\begin{array}{l}0.44 \\
0.35\end{array}$ & & & & & & & & & \\
\hline \multicolumn{14}{|l|}{ Sites B } \\
\hline B1(Asp101 O $\left.{ }^{\delta 2}\right)$ & & & & 0.33 & & & & & & & & & \\
\hline B2 (Asp101 O $\left.\mathrm{O}^{\delta 1} / \mathrm{O}\right)$ & & & & $\begin{array}{l}0.32 \\
0.41\end{array}$ & & & & & & & & & 0.67 \\
\hline B3 (Trp62) & & & & 0.44 & & & & & & & & & \\
\hline Site $\mathrm{C}$ (C-terminus) & & & & & & & & & & 0.39 & 0.62 & 0.72 & 0.46 \\
\hline Site D (Asp87) & & & & & & & & & & & 0.34 & 0.42 & \\
\hline Site E (Asn77) & 0.72 & 0.76 & 0.23 & 0.73 & & & & & & & & & \\
\hline Site F (Asn44) & & & & 0.60 & & & & & & & & & \\
\hline All $\mathbf{C l}^{-} q_{\text {total }}$ & 1.98 & 1.00 & 0.92 & 1.84 & 0.98 & 1.00 & 1.00 & 1.00 & 1.00 & 0.99 & 1.95 & 2.00 & 2.87 \\
\hline Site G (Tyr23) & 1.00 & 1.00 & 0.92 & 0.98 & 0.98 & 1.00 & 1.00 & 1.00 & 1.00 & 0.99 & 1.00 & 1.00 & 0.99 \\
\hline Site H (Ser24) & 0.98 & & & 0.86 & & & & & & & 0.95 & 1.00 & 0.93 \\
\hline Site I (Lys33) & & & & & & & & & & & & & 0.95 \\
\hline
\end{tabular}

$\dagger$ With a final concentration of $30 \%$ glycerol.

cations $\mathrm{Co}^{2+}\left(q_{\mathrm{tot}}=0.54\right), \mathrm{Mn}^{2+}\left(q_{\mathrm{tot}}=0.83\right)$ and $\mathrm{Yb}^{3+}(q=$ 0.99 ) bind to site $\mathrm{A}$, while an additional trivalent cation $\mathrm{Yb}^{3+}$ is found at site $\mathrm{C}$ with an occupancy of 0.39 .

Checking the effect of higher salt concentrations, where the solubility rises, shows that more $\mathrm{Mn}^{2+}$ and $\mathrm{Co}^{2+}$ cations are bound: $q_{\mathrm{tot}}=0.8$ for $\mathrm{Co}^{2+}$ and 1.33 for $\mathrm{Mn}^{2+}$. These cations are bound at the same sites as those seen at lower concentration, but have a higher $q$, and even populate alternate positions for $\mathrm{Mn}^{2+}$.

Only one $\mathrm{Cl}^{-}$is observed in all of these structures in binding site $\mathrm{G}$, with an occupancy ranging from 0.92 to 1.00 .

3.1.2. Data collected at $100 \mathrm{~K}$. Data have been recorded at $100 \mathrm{~K}$ in order to compare the relative binding of the two monovalent cations with each other, as well as to evaluate the effect of temperature on the binding of $\mathrm{Cs}^{+}$and $\mathrm{Yb}^{3+}$.

Site $\mathrm{E}$ is equally occupied by $\mathrm{Rb}^{+}$or the larger $\mathrm{Cs}^{+}$cation (Figs. $2 a$ and $2 b$ ), with $q=0.72$ and 0.73 , respectively. The significant difference comes from the $q_{\text {tot }}$ of the two cations, since $\mathrm{Rb}^{+}$is only present in site $\mathrm{E}$, whereas six further $\mathrm{Cs}^{+}$ cations are observed on the protein surface at site $\mathrm{A} 1(q=$ $0.28)$, site $\mathrm{A} 3(q=0.79)$, site $\mathrm{B} 1(q=0.65)$, site $\mathrm{B} 2(q=0.41)$, site B3 $(q=0.44)$ and a new site, F, with $q=0.60$. The total number of $\mathrm{Cs}^{+}$cations at $100 \mathrm{~K}$ is about 17 times that at room temperature. The crystals were both grown at room temperature, but the flash-cooling for data collection at $100 \mathrm{~K}$ seems to 'freeze' labile $\mathrm{Cs}^{+}$cations, as illustrated by the increase in $q$ at site $\mathrm{E}$ from 0.23 to 0.73 .

The number of bound cations follows the order $\mathrm{Rb}^{+}<<\mathrm{Cs}^{+}$. This corroborates the lower solubility curve of HEWL crystallized in $\mathrm{RbCl}$ than in $\mathrm{CsCl}$ (Fig. 1) at $25^{\circ} \mathrm{C}$.

In contrast to $\mathrm{Cs}^{+}$, the total number of $\mathrm{Yb}^{3+}$ cations at $100 \mathrm{~K}$ is nearly identical to that at room temperature for a $0.5 \mathrm{M}$ salt concentration. This strongly suggests a different type of binding for the two types of cations, as highlighted by the structural analysis at the atomic level in $\$ 3.3$.

There is a unique $\mathrm{Yb}^{3+}$ position at site $\mathrm{A} 1$ at $100 \mathrm{~K}$ instead of the two alternate positions observed at room temperature, and a new site (site D) becomes occupied by an $\mathrm{Yb}^{3+}$ cation $(q=0.34)$.

Comparing now the binding sites in the crystal grown at $0.5 \mathrm{M}$ with that grown at $0.75 M, q_{\text {tot }}$ for $\mathrm{Yb}^{3+}$ increases from 1.51 to 1.89 , whereas the binding of $\mathrm{Cl}^{-}$is nearly identical ( $q_{\text {tot }}$ varying from 1.95 to 2.00), without any new sites for either the cation or the anion.

In these four structures at $100 \mathrm{~K}$ a second $\mathrm{Cl}^{-}$anion is observed in site $\mathrm{H}$ close to Ser24, with $q$ ranging from 0.86 to 1.00 .

3.1.3. Effect of glycerol. A last set of structures were solved from crystals grown in the presence of $30 \%(v / v)$ glycerol, from which data were recorded under cryo-conditions, addressing the effect on ion binding of the presence of this often-used additive. One would expect that electrostatic interactions would be reinforced in the presence of glycerol, since the dielectric constant of the solvent is lowered.

For $\mathrm{Rb}^{+}$there is no significant difference in $q_{\text {tot }}$ or the type or the number of binding sites in the presence and absence of glycerol. In contrast, $q_{\text {tot }}$ for $\mathrm{Yb}^{3+}$ increases from 1.51 to 1.92 with $30 \%$ glycerol and the binding sites change: the occupancy at $\mathrm{A} 1$ is higher than in the absence of glycerol and a new $\mathrm{Yb}^{3+}$ site appears at B1 (Fig. 2c), while A2 and A3 are no longer occupied. The binding at site $\mathrm{C}$ is nearly unchanged.

For $\mathrm{Cl}^{-}$anions, a third $\mathrm{Cl}^{-}$site (at site I) close to Lys33 ( $q=$ $0.95)$ is observed in the presence of glycerol and $\mathrm{YbCl}_{3}$.

\subsection{Types and number of cations identified by ESI-MS}

Three series of ESI-MS investigations were performed. Firstly, crystals from the same set of X-ray diffraction experiments were dissolved in parallel to the X-ray structure determinations in order to search for protein $\mathrm{m} / \mathrm{z}$ increased by bound cations. Secondly, HEWL solutions were prepared with increasing cation concentrations in order to obtain further information on the various HEWL-cation complexes. Finally, an attempt at quantification gives a relative efficiency of the cations for interaction with the protein, although limited by the technical feasibility.

The binding of cations modifies both the mass $m$ and the charge $z$ of the protein complex. For each charge state, additional peaks appear incremented by the mass of the adsorbed 
cations. A given charge state $z$ arises from the sum of the $n$ cations and $z^{\prime}$ protons $\mathrm{H}^{+}$. Similarly, the measured mass $\mathrm{m} / z$ includes the mass of HEWL, the $n$ adsorbed cations and $z^{\prime}$ protons.

3.2.1. Dissolved lysozyme-cation crystals. Since a high salt concentration hampers ionization and a satisfactory signal-tonoise ratio in MS, the HEWL crystals used were those grown at the highest ionic strength compatible with an interpretable MS spectra (indicated by stars in Fig. 1) and dissolved in $200 \mu \mathrm{l}$ pure water prior to injection. All spectra exhibit +8 to +13 charge states for HEWL.

Monovalent $\mathrm{Rb}^{+}$and $\mathrm{Cs}^{+}$. In the MS spectra of HEWL crystals grown in the presence of $\mathrm{RbCl}$ or $\mathrm{CsCl}$, no additional ion peaks were observed up to $0.6 \mathrm{M}$ salt, which is the limit of salt concentration for which the signal-to-noise remains interpretable.

Multivalent cations: $\mathrm{Mn}^{2+}, \mathrm{Co}^{2+}$ and $\mathrm{Yb}^{3+}$. In the spectra of HEWL crystals grown in $0.6 M \mathrm{MnCl}_{2}, 0.5 \mathrm{M} \mathrm{CoCl}_{2}$ or $0.4 \mathrm{M}$

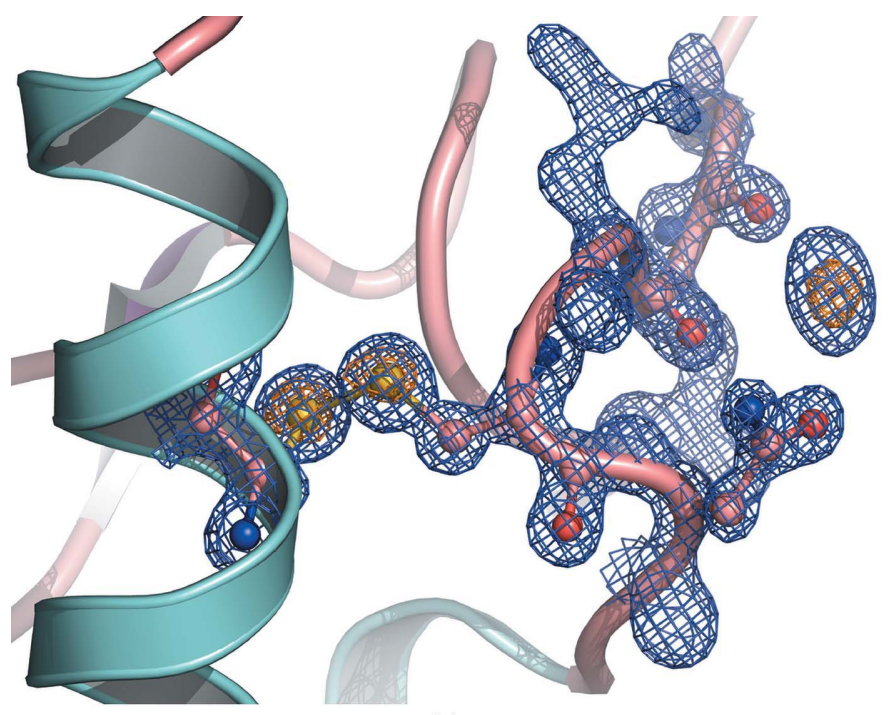

(a)

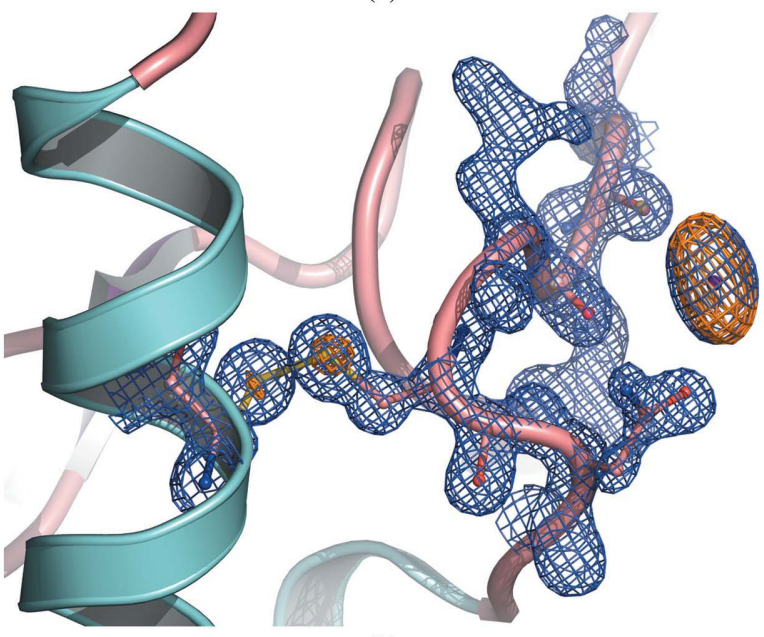

(b)
$\mathrm{YbCl}_{3}$ (top, middle and bottom, respectively, in Fig. 3), the most populated charge state $z$ is +10 . This indicates a similar ionization of the three species and allows their comparison. The highest peak intensities correspond to the addition of 1-2 $\mathrm{Mn}^{2+}$ cations $(n=1-2)$, but to free lysozyme $(n=0)$ in the presence of the two other salts. Further binding of up to five adsorbed $\mathrm{Mn}^{2+}$ cations $(n=5)$, two $\mathrm{Co}^{2+}$ cations and three $\mathrm{Yb}^{3+}$ cations is observed.

These results are in agreement with the $\mathrm{X}$-ray structures revealing that two $\mathrm{Mn}^{2+}$ cations and one $\mathrm{Co}^{2+}$ cation bind to sites A1 and A2. The additional cations detected by MS might be owing to nonspecific adsorption occurring in the MS source or to interactions that cannot be highlighted by crystallography, as this latter technique shows averaged electron density over the unit cells and the time of data collection. They might also be owing to the presence of $\mathrm{MeOH}$ added to enhance the signal and which reinforced electrostatic interactions as observed for glycerol by crystallography. This motivated us to address the binding of cations in solution as described below.

3.2.2. Lysozyme-cation complexes in ammonium acetate buffer solutions. The results obtained by ESI-MS analyses for dissolved crystals have been supplemented by analyses of HEWL in solution to which increasing amounts of salts have been added at relatively low concentrations in order to address a possible mechanism of adsorption.

When HEWL $(2 \mu M)$ is in an aqueous solution brought to pH 4.7 with $\mathrm{HCl}$, the MS spectrum (Fig. 4, top) shows the classical expected profile (Riès-Kautt et al., 1994) with +8 to +13 charge states with $m / z$ 1101.82, 1193.60, 1301.87, 1431.71, 1590.81 and 1789.25 . The average molecular weight is $14305 \pm$ $2 \mathrm{Da}$, consistent with the mass calculated from its chemical formula minus eight $\mathrm{H}$ atoms for the four disulfide bridges.

Several papers have correlated the number and values of the protein charged states with the ability of the protein to partially unfold in acidic or organic solvents or to preserve

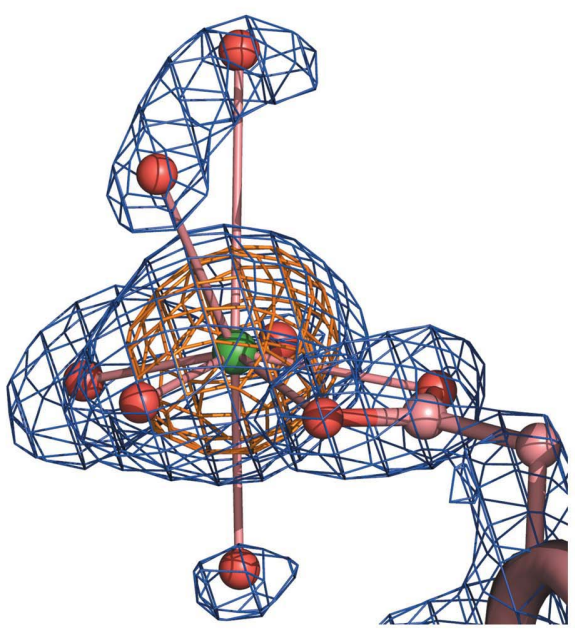

(c)

Figure 2

Anomalous difference and $\sigma_{\mathrm{A}}$-weighted electron-density maps for $\mathrm{Rb}^{+}(a)$ and $\mathrm{Cs}^{+}(b)$ at binding site $\mathrm{E}$ and $\mathrm{Yb}^{3+}(c)$ at binding site $\mathrm{B} 1$. $\left(2 m F_{\mathrm{obs}}-\right.$ $D F_{\text {calc }}$ ) electron-density maps (blue) are contoured at 1.7 $\sigma$. Anomalous difference maps (orange) are contoured at 3.6 $\sigma$. (a,b) Electron-density maps are drawn around residues Arg73-Asn77, Cys94 and the cation. The disulfide bridge between Cys76 and Cys94 is also shown for comparison of anomalous signals. Cation-binding atoms of HEWL are shown: $\mathrm{C}=\mathrm{O}$ of Arg73 and Asn74, as well as the side chain of Asn77 (for clarity the other atoms are hidden). 
Table 4

Calculated and experimental molecular weights of [HEWL ${ }^{z+}+n$ cations].

\begin{tabular}{|c|c|c|c|c|c|c|c|c|c|}
\hline \multirow[b]{4}{*}{ Cation } & \multirow[b]{4}{*}{ Atomic mass } & \multicolumn{8}{|c|}{ Molecular mass of HEWL $+n$ cation(s) (Da) } \\
\hline & & \multicolumn{3}{|c|}{ Calculated } & \multicolumn{5}{|c|}{ Experimental $( \pm 3) \dagger$} \\
\hline & & \multirow[b]{2}{*}{$n=0$} & \multirow[b]{2}{*}{$n=1$} & \multirow[b]{2}{*}{$n=2$} & \multicolumn{3}{|l|}{$z=8$} & \multicolumn{2}{|l|}{$z=9$} \\
\hline & & & & & $n=0$ & $n=1$ & $n=2$ & $n=0$ & $n=1$ \\
\hline Cs & 132.91 & 14305 & 14438 & 14571 & 14307 & 14441 & - & 14306 & - \\
\hline $\mathrm{Mn}$ & 54.94 & & 14360 & 14415 & 14304 & 14363 & 14414 & 14308 & 14361 \\
\hline Co & 58.93 & & 14364 & 14423 & 14306 & 14365 & 14425 & 14306 & 14365 \\
\hline $\mathrm{Yb}$ & 173.04 & & 14478 & 14651 & 14307 & 14479 & 14652 & 14308 & 14479 \\
\hline
\end{tabular}

$\dagger$ Average value based on 3-12 ESI-MS measurements.
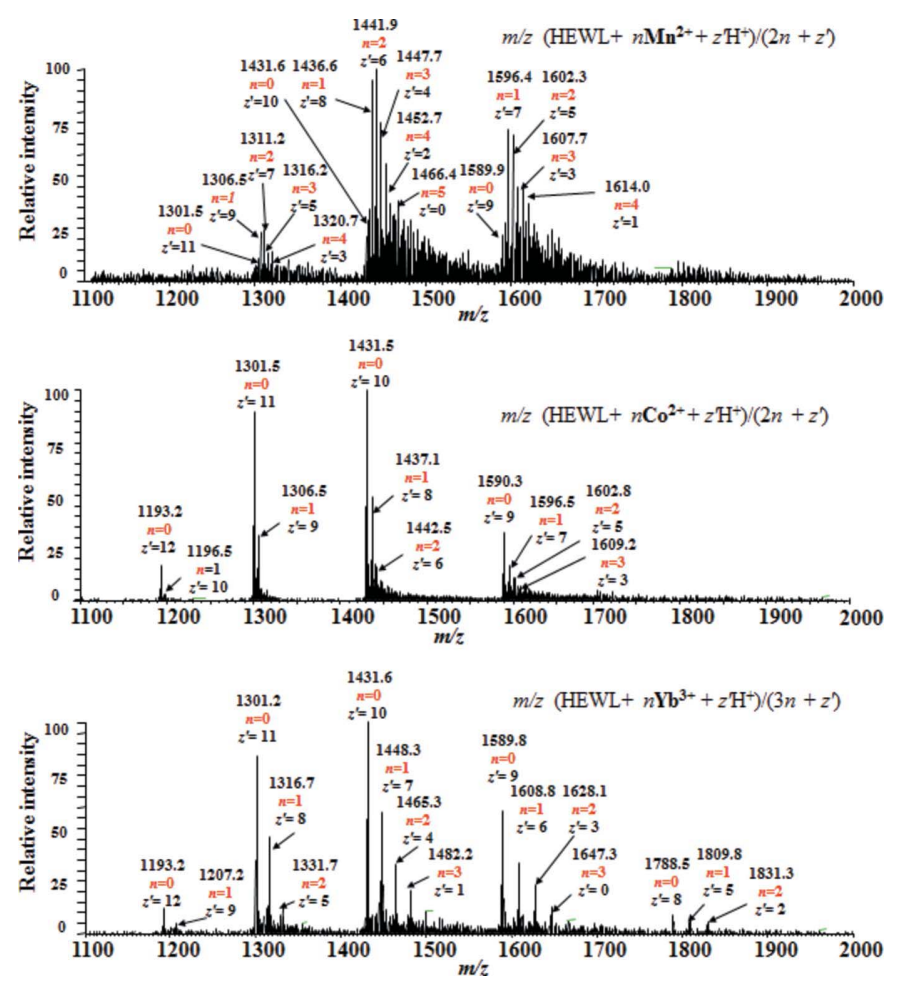

Figure 3

ESI-MS spectra of HEWL crystals dissolved in water.
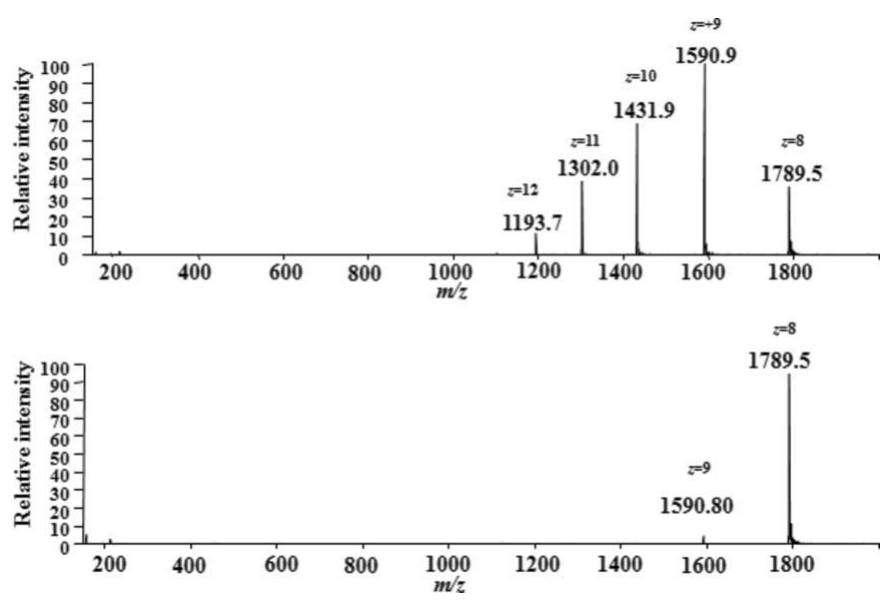

Figure 4

ESI-MS spectra of free HEWL in 85:15(v:v) water:MeOH brought to $\mathrm{pH}$ 4.5 with $\mathrm{HCl}$ (top) and in $20 \mathrm{mM}$ ammonium acetate (bottom). its native conformation in ammonium salts (Winston \& Fitzgerald, 1997; Pramanik et al., 1998; Heck \& Van Den Heuvel, 2004) during transfer into the gas phase, including a recent study by ion-mobility MS (Angel, 2011). Although HEWL is known to be a very robust protein (Mao et al., 2003), which undergoes no irreversible changes or loss of activity between $\mathrm{pH} 2.7$ and 11 (Tanford \& Wagner, 1954), we preferred to run the titration analysis in ammonium acetate. Indeed, the HEWL mass spectrum (Fig. 4, bottom) in $20 \mathrm{~m} M$ ammonium acetate buffer pH 4.5 exhibits only two charge states: $z=9$ and $z=8$. Deconvolution of 24 spectra leads to an experimental average mass of $14306 \pm 2$, identical to that measured in $\mathrm{HCl} /$ water within the measurement accuracy, and is in agreement with no disruption of the disulfide bridges.

Comparing the two spectra, they mainly differ in the number of charged states (two instead of five) and in the most intense peak being +8 instead of +9 . The reduced charge states observed in ammonium acetate might be attributed to ammonia participating in gas-phase proton-transfer reactions with multi-charged lysozyme (Lemaire et al., 2001). Using ammonium acetate-buffered conditions yields a nearly single ionization state with an improved signal-to-noise ratio and is more favourable for investigating the adsorption by a semiquantitative approach.

Ammonium-buffered HEWL solutions [20 $\mathrm{m} M$ ammonium acetate buffer $\mathrm{pH} 4.5$ with $15 \%(v / v)$ methanol] were mixed with increasing concentrations of metal cation ranging from 20 to $600 \mu M$. Above $600 \mu M$ salt the spectra become too perturbed by the presence of salt, especially when one recalls that the ionic strength equals three times the concentration of $\mathrm{MnCl}_{2}$ or $\mathrm{CoCl}_{2}$ and six times the salt concentration of $\mathrm{YbCl}_{3}$.

At $100 \mu M$ cation chlorides, corresponding to a HEWL: cation ratio of 1:50, the spectra (Fig. 5) show an ion peak corresponding to free lysozyme $(n=0)$ together with a peak for a HEWL complex with one cation $(n=1)$, except for $\mathrm{Cs}^{+}$. Indeed, there is no peak owing to adsorption of $\mathrm{Cs}^{+}$at this salt concentration. In the presence of $350 \mu M \mathrm{Mn}^{2+}, \mathrm{Co}^{2+}$ or $\mathrm{Yb}^{3+}$ (i.e. a HEWL:cation ratio of 1:175) a second peak appears corresponding to two adsorbed cations per protein molecule. Only a single cation is adsorbed in the case of $\mathrm{Cs}^{+}$at this concentration.

The experimental values of the different species are in agreement with the calculated values as shown in Table 4.

To conclude on the qualitative aspects, we were able to observe the adsorption of one and then two multivalent cations onto lysozyme molecules, but barely one monovalent $\mathrm{Cs}^{+}$.

3.2.3. Titration curves. The signal intensities for free lysozyme $(n=0)$ and for HEWL-cation complexes $(n=1$ or 2$)$ were summed for the two protein charge states $z=9$ and $z=8$ over the whole range of salt concentrations. Fig. 6 shows the titration curves with the decrease of free HEWL and the 
appearance of HEWL bearing one and two cations as a function of the salt concentration.

Increasing the concentration from 20 to $600 \mu \mathrm{M} \mathrm{Mn}^{2+}, \mathrm{Co}^{2+}$ or $\mathrm{Yb}^{3+}$ induces a decrease in free HEWL and the appearance of lysozyme complexes with one and then two bound cations. In contrast, increasing the $\mathrm{Cs}^{+}$concentration produces only a slight decrease in free HEWL concomitant with the formation of $10 \% \mathrm{HEWL}$ in complex with one $\mathrm{Cs}^{+}$.

We must first emphasize that saturation was not reached in any of these MS experiments and therefore further quantitative conclusions, such as defining an association constant, for example, cannot be drawn. At the highest investigated salt concentration, $90 \%$ of the $\mathrm{HEWL}$ remains free in $\mathrm{CsCl}, 60 \%$ in $\mathrm{YbCl}_{3}$ and approximately $30-40 \%$ in $\mathrm{MnCl}_{2}$ and $\mathrm{CoCl}_{2}$ (Fig. 7). The fraction of HEWL complex with one cation is $\leq 10 \%$ in $\mathrm{CsCl}$ but is $\simeq 30 \%$ for the multi-charged cations. Complexes with two cations account for $20 \%$ for $\mathrm{Mn}^{2+}$ or $\mathrm{Co}^{2+}$ and $10 \%$ for $\mathrm{Yb}^{3+}$. Finally, HEWL complexes with three cations represent about $10 \%$ of the species with $\mathrm{Mn}^{2+}$ and $\mathrm{Co}^{2+}$ within experimental error.

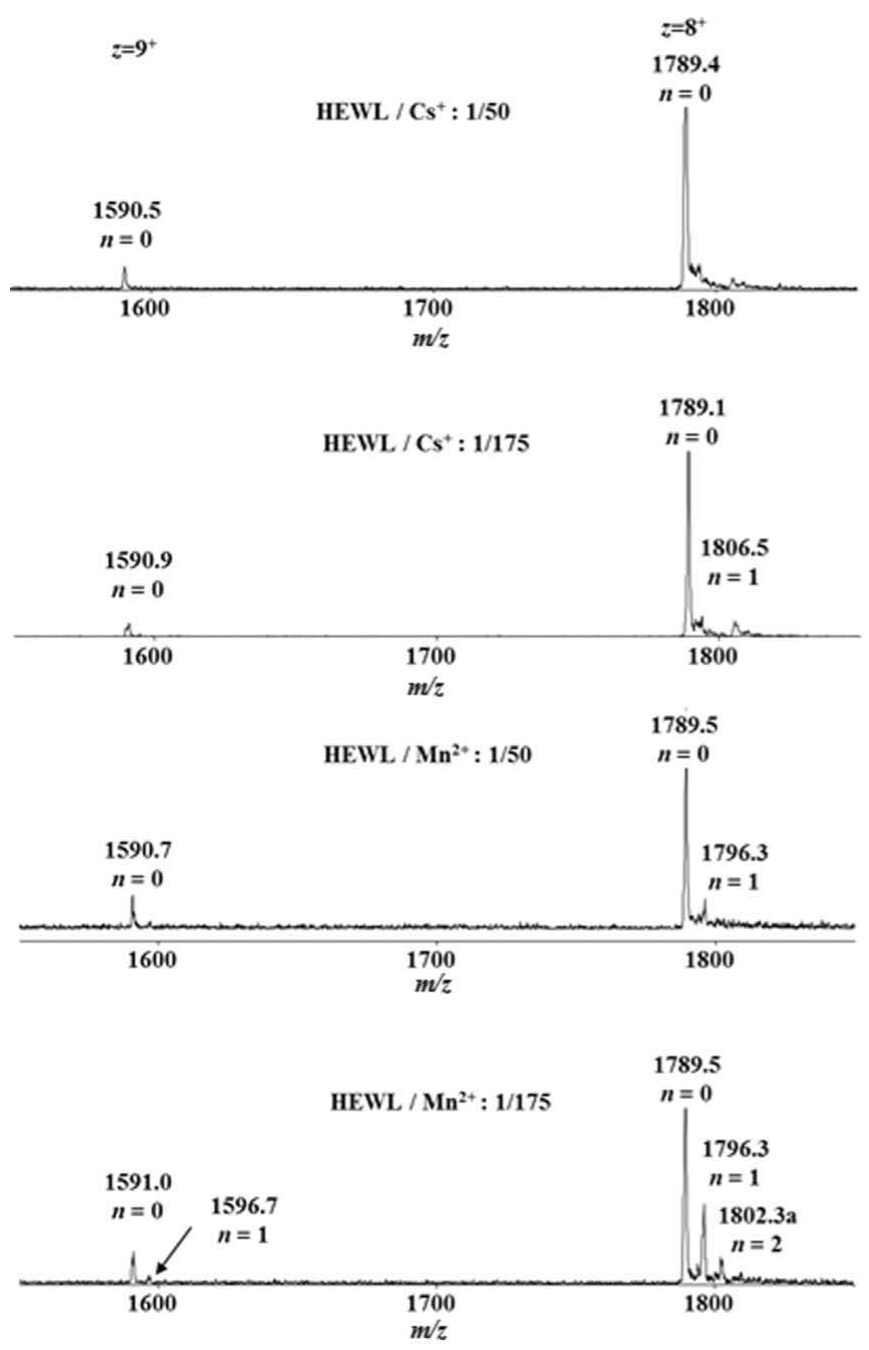

From these results, we can estimate the total amount of each type of bound cation by multiplying the number $n$ of cations by their fraction. For example, $30 \%$ of HEWL molecules bind one $\mathrm{Mn}^{2+}$ cation $\left(0.3 \mathrm{Mn}^{2+}\right), 20 \%$ bind two $\mathrm{Mn}^{2+}$ cations $(0.4)$ and $10 \%$ bind three $\mathrm{Mn}^{2+}$ cations (0.3), giving a total of one bound $\mathrm{Mn}^{2+}$ per HEWL molecule on average. The same calculation gives about $0.1 \mathrm{Cs}^{+}$cation, $0.5 \mathrm{Yb}^{3+}$ cation and about one $\mathrm{Co}^{2+}$ cation.

These ESI-MS results at $600 \mu M$ salt suggest that the number of bound cations follows the order $\mathrm{Cs}^{+}<<\mathrm{Yb}^{3+}<$ $\mathrm{Co}^{2+} \simeq \mathrm{Mn}^{2+}$. Although it might be tempting to compare these values with $q_{\text {tot }}$ obtained from the X-ray structures, we must be aware that here the HEWL-cation complexes are studied in a gas phase far from the crystal-solution equilibrium and strongly depend on their ionization ability. Ions trapped owing to crystal packing, such as $\mathrm{Yb}^{3+}$ at the C-terminus (site $\mathrm{C}$ ) are not expected to be observed using this approach. Moreover, we have already underlined that ESI-MS analysis requires some $\mathrm{MeOH}$ to enhance the signal and we have seen that the addition of organic species might act differently in the binding

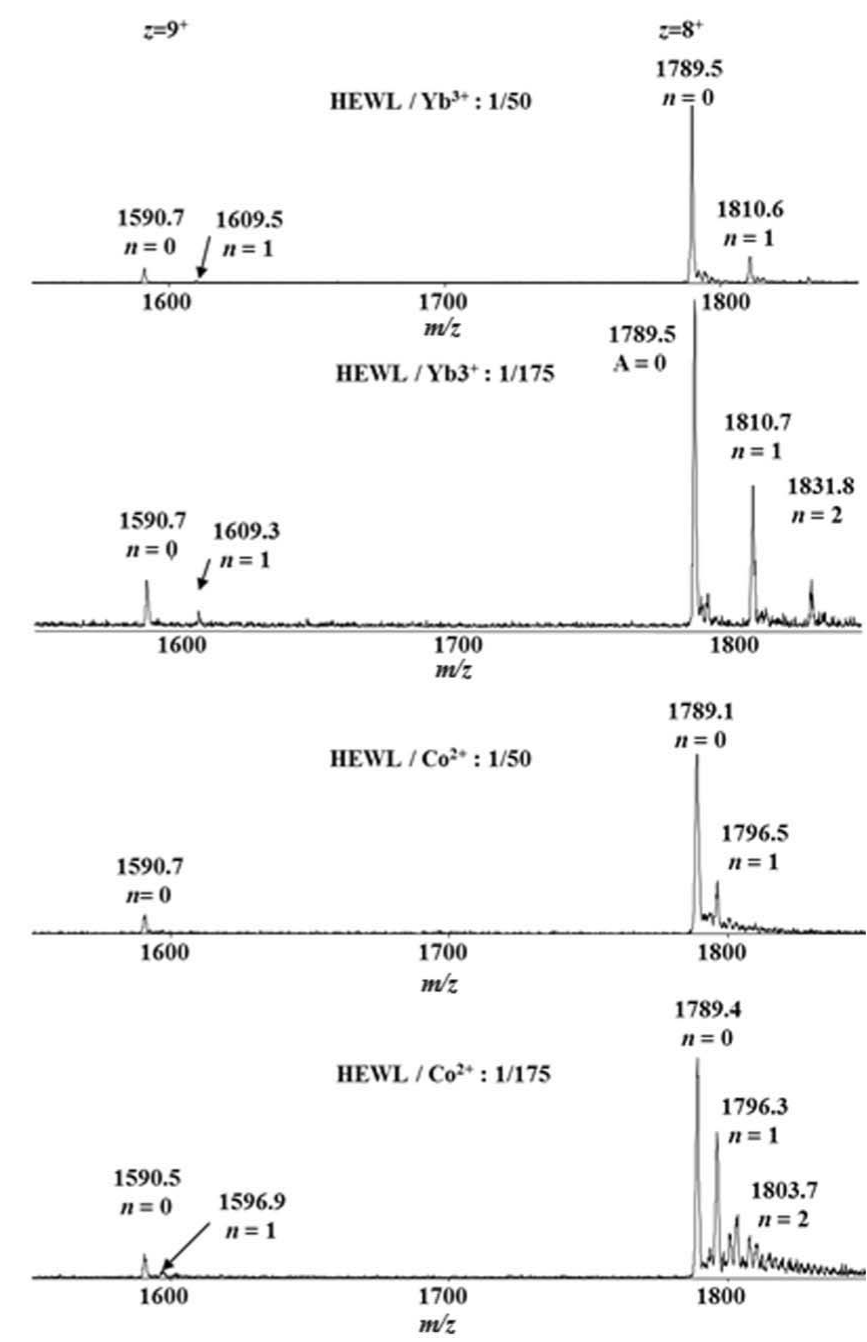

Figure 5

ESI-MS mass spectra of HEWL $(2 \mu M)$ in $20 \mathrm{~m} M$ ammonium acetate $\mathrm{pH} 4.5$ buffer in 85:15(v:v) water:MeOH at two concentrations of added cations: protein:cation ratios of 1:50 (i.e. $100 \mu M$ salt) and 1:175 (i.e. $350 \mu M$ salt) as indicated. $\mathrm{Cs}^{+}$, top left; $\mathrm{Yb}^{3+}$, top right; $\mathrm{Mn}^{2+}$, bottom left; $\mathrm{Co}^{2+}$, bottom right. 

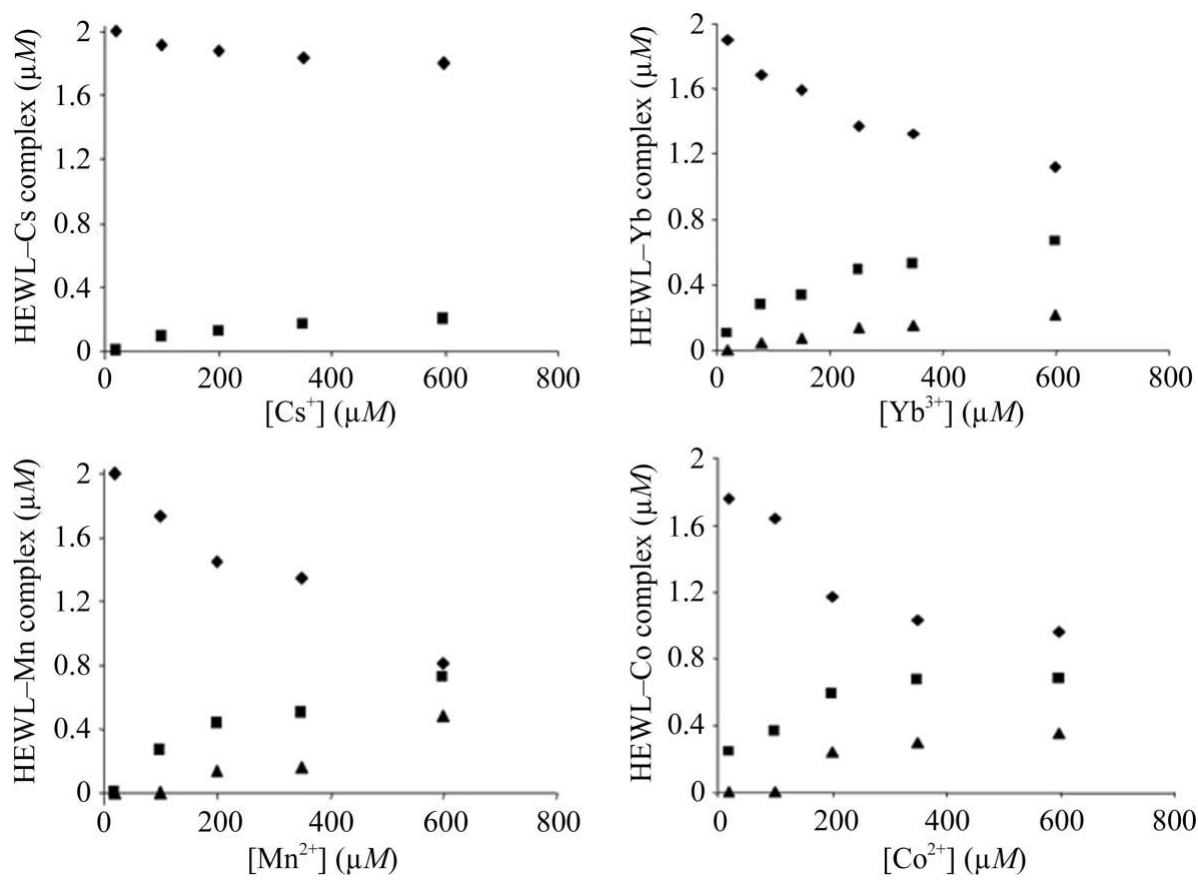

Figure 6

HEWL titration curves measured by ESI-MS. Concentration with 0 (diamonds), 1 (squares; $n=1$ ) and 2 (triangles; $n=2$ ) adsorbed cations versus salt concentration $(\mu M)$ in solution: $\mathrm{Cs}^{+}$, top left; $\mathrm{Yb}^{3+}$, top right, $\mathrm{Mn}^{2+}$, bottom left; $\mathrm{Co}^{2+}$, bottom right.

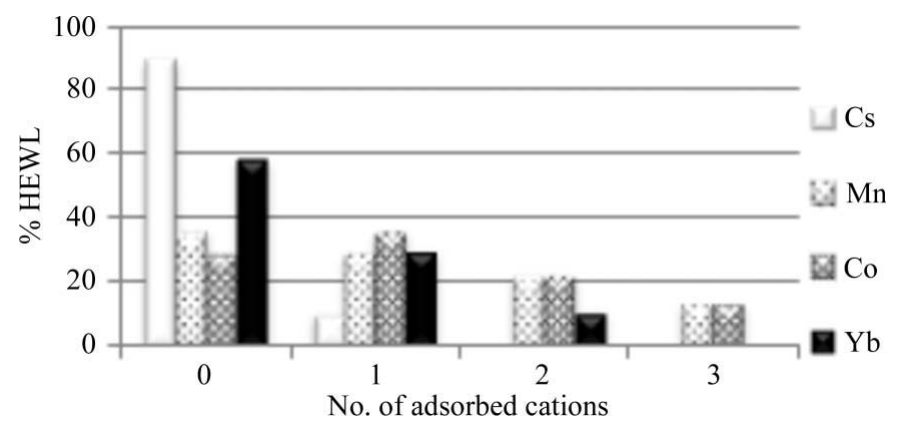

Figure 7

Percentage of free HEWL and as a complex with 1-3 cations at $600 \mu M$ salt.

of monovalent cations compared with multivalent cations for crystals grown in the presence of glycerol.

\subsection{Ion-binding sites}

The X-ray analysis allowed the identification of 13 different ion-binding areas (A-I) on the HEWL surface, ten binding cations and three binding chlorides, as illustrated in Fig. 8. The locations of the cation-binding sites $(\mathrm{A}-\mathrm{F})$ and $\mathrm{Cl}^{-}(\mathrm{H}-\mathrm{I})$ are shown together with the electronegative (red) and positive (blue) surface areas of the protein. The areas A and B are subdivided into three binding sites each, as detailed below.

The shortest binding distances measured in the reported $\mathrm{X}$-ray structures are listed in Table 5.

3.3.1. Binding zone $\mathrm{A}: \mathrm{Cs}^{+}, \mathrm{Mn}^{2+}, \mathrm{Co}^{2+}$ and $\mathrm{Yb}^{3+}$. The cations of binding zone $\mathrm{A}$ are found either close to the carboxyl of Asp52 (site A1), that of Glu35 (A2) or the carbonyl of Asn46 (A3). The glycoside hydrolase activity of lysozyme is known to involve Asp52 and Glu35 lying in the catalytic cleft (Vocadlo et al., 2001), but no ions participate in the activity.

In the structures at room temperature, $\mathrm{Co}^{2+}, \mathrm{Mn}^{2+}$ and $\mathrm{Yb}^{3+}$ are all bound to Asp52 $\mathrm{O}^{\delta 2}$ of site A1 (Fig. 9). $\mathrm{Co}^{2+}$, the smallest of the three cations, binds only to this unique site (yellow ball), with a higher occupancy on increasing the ionic strength. It is close to five water molecules at distances of 2.0-2.5 $\AA$. Asp52 $\mathrm{O}^{\delta 2}$ binds one $\mathrm{Mn}^{2+}$ cation at $0.5 M$ but three at $1.1 M$ (Fig. 9 , right) in alternate positions. $\mathrm{Mn}^{2+}$ is also at a short distance from three water molecules. There are two alternate positions in site $\mathrm{A} 1$ for the largest $\mathrm{Yb}^{3+}$ cation and four water molecules are at short or medium distances depending on the data set.

In addition to site $\mathrm{A} 1$ a further $\mathrm{Mn}^{2+}$ cation is bound to the Glu35 carboxylic group (site A2) at $0.5 \mathrm{M}$ as well as at 1.1 $\mathrm{M} \mathrm{MnCl}_{2}$. This site is also occupied by a $\mathrm{Yb}^{3+}$ cation (Fig. 9, left) but not by $\mathrm{Co}^{2+}$. Site A2 is clearly separate from site A1, taking the distances into account and the sum of the refined occupancies, which would greatly exceed $100 \%$ in the crystal structure at $1.1 \mathrm{M} \mathrm{MnCl}_{2}$.

For monovalent cations, no anomalous signal is observed in binding zone $\mathrm{A}$ among the structures at room temperature, unlike in the structure of $\mathrm{HEWL}$ in $\mathrm{CsCl}$ at $100 \mathrm{~K}$. Indeed, three $\mathrm{Cs}^{+}$cations are identified: one at site A1 and two at A3. The latter are alternate positions interacting with the carbonyl of Asn46. In all of the structures presented in this work, only Cs occupies site A3.

3.3.2. Binding zone $\mathrm{B}$ : $\mathrm{Cs}^{+}$and $\mathrm{Yb}^{3+}$. Binding zone $\mathrm{B}$ involves Asp101 and is about $16 \AA$ from the catalytic cleft. Similarly to site A, it is subdivided into three sites: the cation is bound to Asp101 $\mathrm{O}^{\delta 2}$ at B1, to Asp101 $\mathrm{O}^{\delta 1}$ and to the carbonyl of the main chain at B2 and to Trp62 $\mathrm{C}^{\delta 1}$ at B3. In this zone, anomalous signals in difference Fourier maps were only observed in cryo-conditions for $\mathrm{Cs}^{+}$and $\mathrm{Yb}^{3+}$ (PDB entries 4ng8 and 4ngz, respectively).

One $\mathrm{Yb}^{3+}$ cation interacts with both Asp101 $\mathrm{O}^{\delta 1}$ and Asp101 $\mathrm{O}^{\delta 2}$ in site B1 (Fig. 10). This cation (green ball in Fig. 2c) is bound to the $\mathrm{O}$ atoms (red balls in Fig. 2c) of water molecules and of the carboxylic group of Asp101 by a bidentate coordination, in contrast to the $\mathrm{Yb}^{3+}$ cation in $\mathrm{A} 1$. The two upper apical water molecules are in alternate positions.

Four $\mathrm{Cs}^{+}$cations occupy site B (Fig. 10): two bound to Asp101 $\mathrm{O}^{\delta 2}$ at $\mathrm{B} 1$, one to Asp101 $\mathrm{O}^{\delta 1}$ and one interacting with the Trp62 indole group at B3, with the latter being in an alternate position with one $\mathrm{Cs}^{+}$at $\mathrm{B} 1$. 

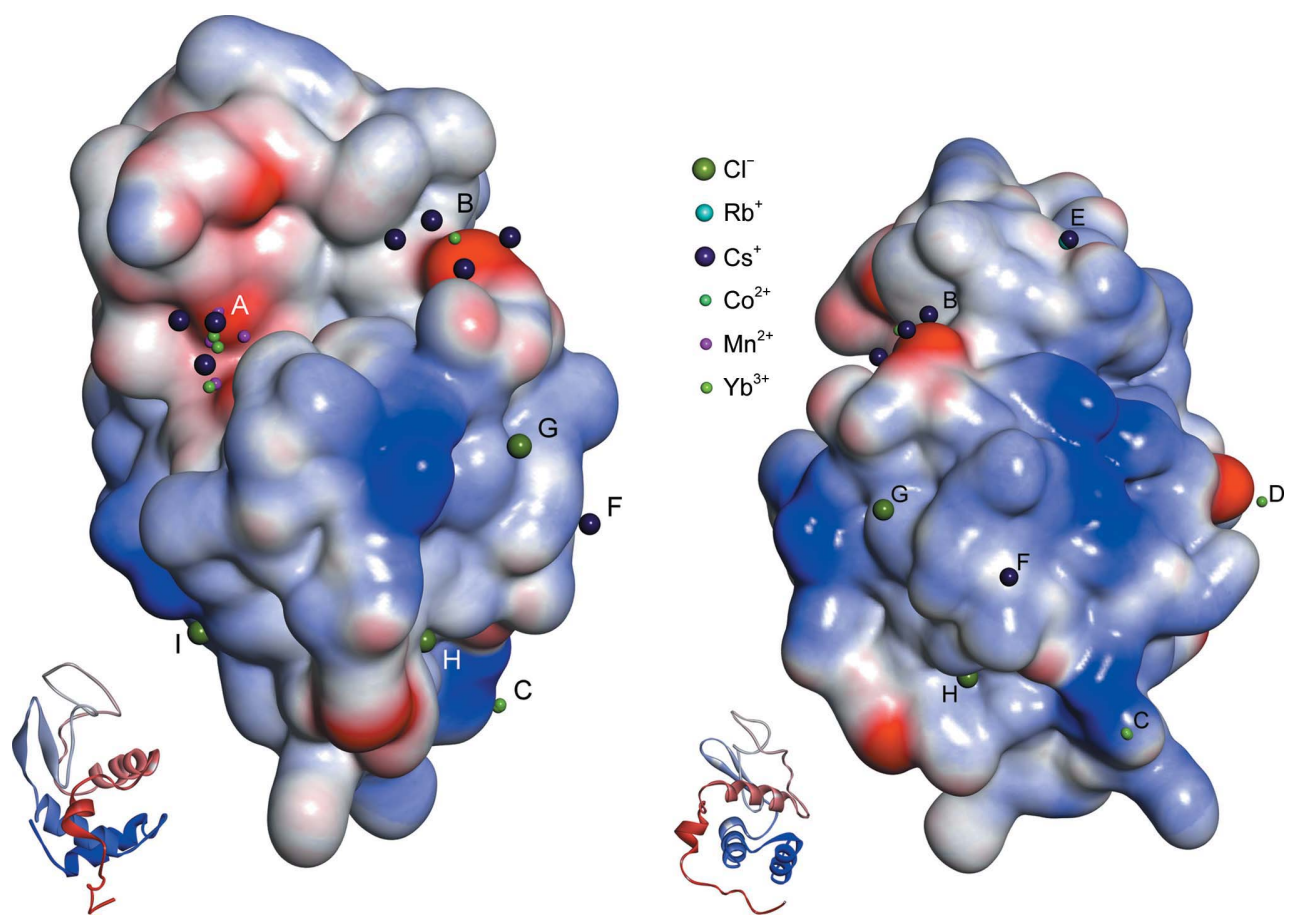

Figure 8

Ion-binding zones on HEWL. The mapping is a superimposition of the cation locations of the different HEWL structures onto PDB entry 4ngz represented by its electrostatic potential surface coloured from negative (red) to positive (blue) values. The two views are at $90^{\circ}$ to each other. The ions are represented by a ball size proportional to their actual ionic radius and are coloured according to the chart. The insets at the bottom represent the HEWL secondary-structure elements coloured from the $\mathrm{N}$-terminus (red) to the C-terminus (blue).

A major difference is observed between $\mathrm{Cs}^{+}$and $\mathrm{Yb}^{3+}$ since the binding of the former involves carbonyl groups whereas that of $\mathrm{Yb}^{3+}$ does not as it only binds to carboxylic acid groups.

3.3.3. Binding sites $\mathbf{C}$ and $\mathbf{D}: \mathbf{Y b}^{3+}$. In all HEWL structures with $\mathrm{Yb}^{3+}$ there is one $\mathrm{Yb}^{3+}$ cation bound to the C-termini of the two symmetry-related protein molecules (site $\mathrm{C}$ ) as shown in Fig. 11. The occupancy is higher at $0.75 M$ than at $0.50 M$, as indicated in Table 3.

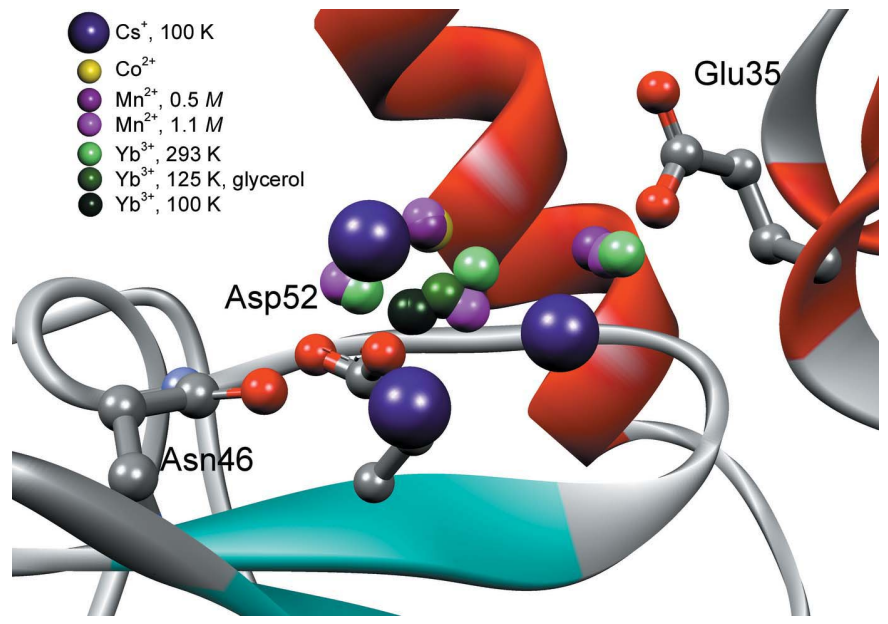

Figure 9

Cation localizations in binding zone A depending on the crystallization and/or data-collection conditions.
Similarly to site $\mathrm{C}$, only $\mathrm{Yb}^{3+}$ is observed bound to Asp87 $\mathrm{O}^{\delta 2}$ (site D), and only for the data recorded at $100 \mathrm{~K}$.

3.3.4. Sites $\mathrm{E}$ and $\mathrm{F}$ : $\mathbf{R b}^{+}$and $\mathrm{Cs}^{+}$. The most interesting finding here is that only carbonyl groups bind the monovalent cations, as observed for binding zone B: $\mathrm{Rb}^{+}$and $\mathrm{Cs}^{+}$both interact with Asn $74 \mathrm{O}$ and Asn77 $\mathrm{O}^{\delta 1}$ as well as with the main-chain carbonyl of $\operatorname{Arg} 73$ at site E (Fig. 8). Binding site $\mathrm{E}$ appears to be specific for monovalent cations, since no anomalous signal can be detected in the structures involving divalent or trivalent cations.

Another $\mathrm{Cs}^{+}$is found in site $\mathrm{F}$, interacting with the carbonyl groups of Asn19 and Asn44, with an occupancy of 0.60 at $100 \mathrm{~K}$.

3.3.5. Chloride-binding sides $\mathbf{G}, \mathbf{H}$ and $\mathbf{I}$. In all of the structures solved in this work, a $\mathrm{Cl}^{-}$ anion is found bound to Tyr23 OH (site G). In structures obtained using data collected under cryoconditions, a second $\mathrm{Cl}^{-}$anion is observed bound to Ser24 $\mathrm{O}^{\gamma}$ and Gly26 NH. A third chloride anion is finally identified interacting with Lys33 in the HEWL structure crystallized in $0.48 \mathrm{M} \mathrm{YbCl}_{3}, 30 \%$ glycerol, from which data were collected under cryoconditions (PDB entry 4ngz).

All of these sites G-I have previously been described as anion-binding sites of HEWL (Dauter et al., 1999; Vaney et al., 2001).

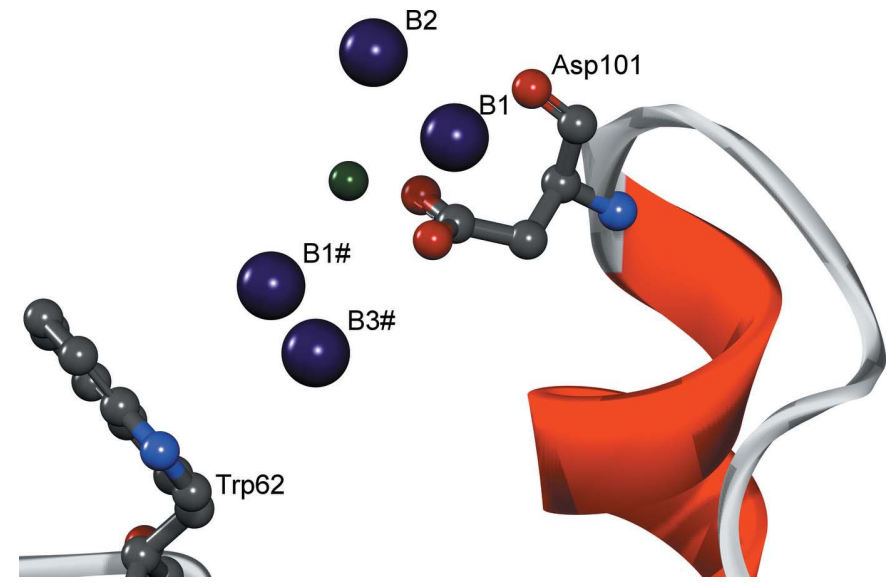

Figure 10

Binding zone $\mathrm{B}$ with four $\mathrm{Cs}^{+}$and one $\mathrm{Yb}^{3+}$ cations in the three sites involving Asp101 $\mathrm{O}^{\delta 1}$, Asp101 $\mathrm{O}^{\delta 2}$ and Asp101 O. $\left(\mathrm{Cs}^{+}\right.$, large indigo balls; $\mathrm{Yb}^{3+}$, green). Alternate $\mathrm{Cs}^{+}$positions are marked \#. 
Table 5

Shortest ion-binding distances $(\AA)$ for each type of cation and for $\mathrm{Cl}^{-}$in the different HEWL structures.

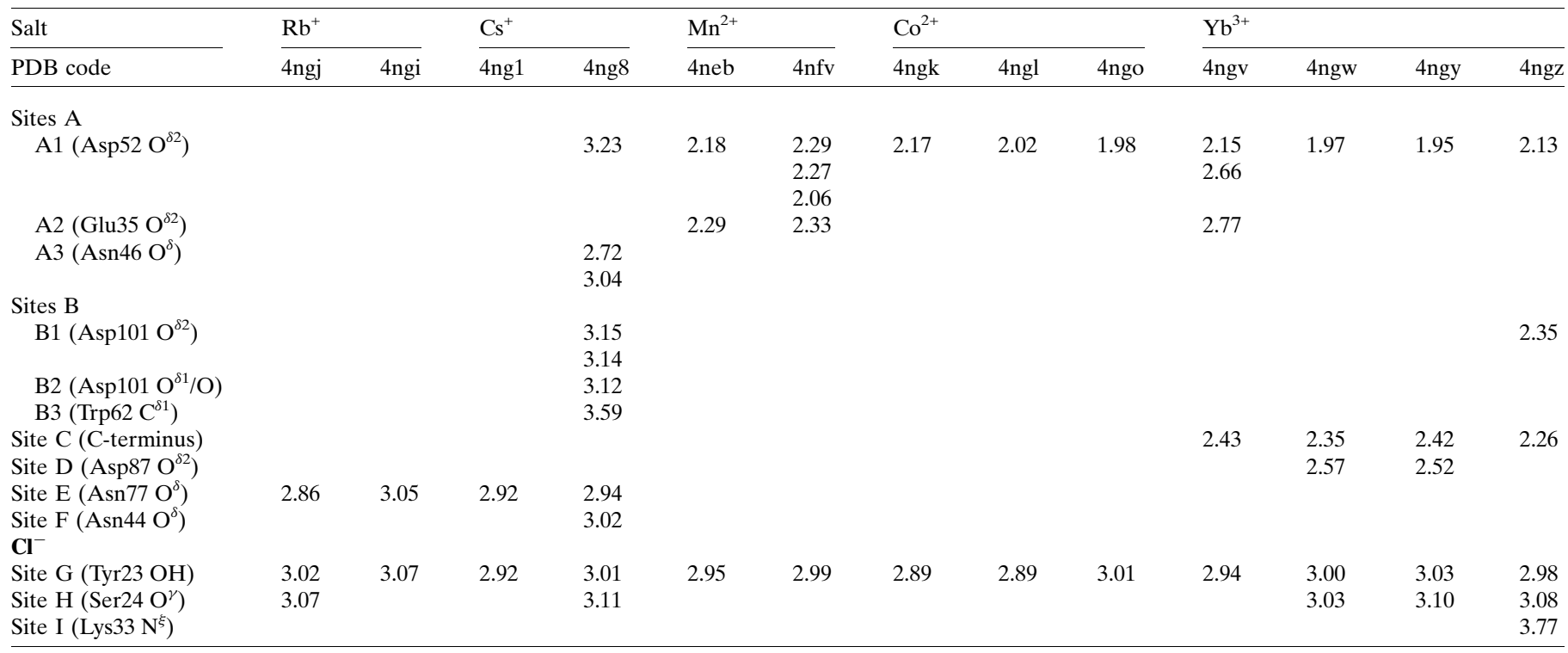

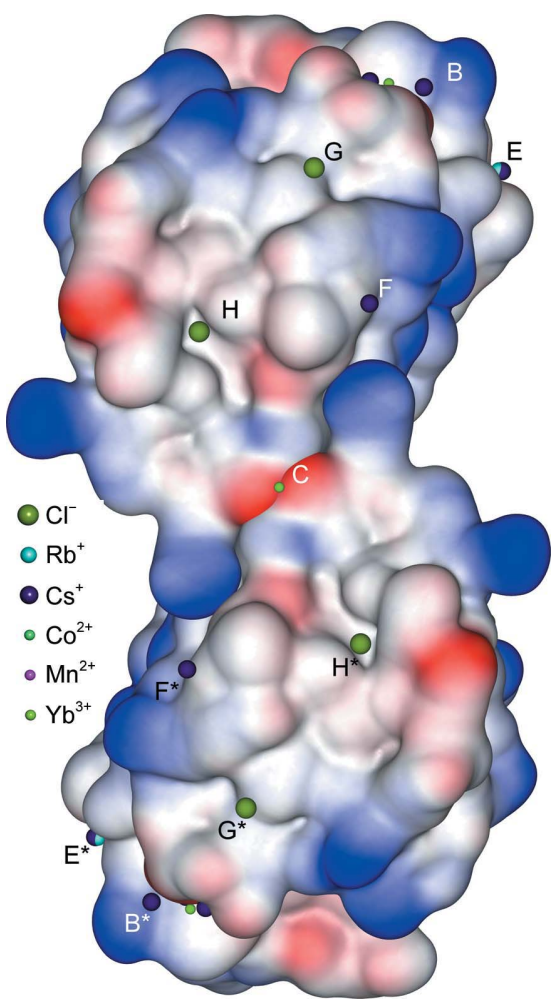

Figure 11

$\mathrm{Yb}^{3+}$ bound to site $\mathrm{C}$ involving the $\mathrm{C}$-termini of two symmetry-related HEWL molecules. On the electrostatic potential surface of HEWL (same colour code as in Fig. 8) the cations are represented by a ball size proportional to their ionic radius and are coloured according to the chart.

\section{Conclusions}

Both the X-ray and the ESI-MS results presented in this study answer the first question addressed in this work by providing previously lacking experimental evidence to explain how these co-ions influence the solubility of the positively charged protein. This work therefore contributes to the elucidation of salt effects and extends Hofmeister's multivalent cation series. Cations interact more weakly as co-ions with proteins than do anionic counter-ions; the highest cation occupancy among the structures presented in this study remains lower than that of $\mathrm{Cl}^{-}$. This is owing to their coordination requirements and of their different solvation in $\mathrm{H}_{2} \mathrm{O}$, since they interact with the $\mathrm{O}$ atoms of water molecules while anions point towards the $\mathrm{H}$ atoms.

Moreover, our results allow progress in the understanding of ion-protein interactions, especially in the relative contributions of hydration and electrostatics.

\subsection{The monovalent and multivalent cations bind to different types of protein binding sites}

The large monovalent $\mathrm{Rb}^{+}$and $\mathrm{Cs}^{+}$cations (ionic radius 1.5-1.7 $\AA$ ) preferentially interact with the carbonyl groups of the HEWL molecule, while the smaller multivalent $\mathrm{Co}^{2+}, \mathrm{Mn}^{2+}$ and $\mathrm{Yb}^{3+}$ cations $(0.7-0.9 \AA)$ preferably bind to the carboxyl groups of the Asp and Glu side chains or of the main-chain C-terminus.

$\mathrm{Rb}^{+}$and $\mathrm{Cs}^{+}$are chaotropic ions with a low charge density and poor hydration. They interact more favourably with the carbonyl groups of the protein via an ion-dipole interaction than with the charged and more hydrated carboxylic acids, as predicted by the law of matching water affinity. The occupancy is reinforced in the structures from the cryo data sets. In the various $\mathrm{X}$-ray structures involving $\mathrm{Rb}^{+}$or $\mathrm{Cs}^{+}$there is no water molecule at a short distance $(<2.5 \AA)$. The smaller $\mathrm{Rb}^{+}$is less bound than the larger $\mathrm{Cs}^{+}$according to the observations from the X-ray and ESI-MS analyses.

The multivalent $\mathrm{Co}^{2+}, \mathrm{Mn}^{2+}$ and $\mathrm{Yb}^{3+}$ cations bind to carboxylic groups on the protein surface via Coulombic interactions, which are less sensitive to temperature than are 
ion-dipole interactions. Carboxylic groups are known to be strongly hydrated with a high charge density, characterizing them as kosmotropes (Collins, 2004). With respect to inner sphere ion-pair formation, carboxylic groups are presumed to interact more favourably with small cations that also bear a high charge density (Collins, 2006), i.e. that are highly hydrated. Water molecules are indeed observed at a short distance $(<2.5 \AA)$ from the cation depending on the data set.

Overall, our experimental results provide experimental insights to explain the contribution of the chemistry of the salt effect in terms of favourable interactions of soft ions with soft protein sites or of hard ions with hard protein sites (Collins, 2012).

\subsection{The efficiency of the cations in affecting protein solubility}

HEWL solubility decreases until the salt concentration reaches about $0.5 \mathrm{M}$, whatever the cation. The solubility continues to decrease when increasing the monovalent cation concentration, but increases with multivalent cations. The different results presented in this study clarify the solubility behaviour, providing the following considerations.

The ESI-MS titration shows the binding of about $0.1 \mathrm{Cs}^{+}$, $0.5 \mathrm{Yb}^{3+}$, one $\mathrm{Mn}^{2+}$ and one $\mathrm{Co}^{2+}$ cations per HEWL molecule at $600 \mu M$ salt, suggesting that the number of bound cations follows the order $\mathrm{Cs}^{+}<<\mathrm{Yb}^{3+}<\mathrm{Mn}^{2+} \simeq \mathrm{Co}^{2+}$, in agreement with the law of matching water affinity, i.e. the order of their hydration.

The number of bound cations ( $\left.q_{\text {tot }}\right)$ from the X-ray structure additionally includes cations from crystal packing. This is the case for $\mathrm{Yb}^{3+}$ at site $\mathrm{C}$ at the interface of two symmetrical HEWL molecules.

Furthermore, it must be underlined that binding a trivalent cation increases the apparent net charge of the resulting protein polyelectrolyte more, and hence its solubility, than a divalent cation does.

Owing to these considerations, the ranking of the cation effect on HEWL solubility becomes $\mathrm{Cs}^{+}<<\mathrm{Mn}^{2+} \simeq \mathrm{Co}^{2+}<$ $\mathrm{Yb}^{3+}$.

A noteworthy outcome of this work is the coherence between the two biophysical approaches to address ionprotein interactions, although cation binding to the protein is different in the gas phase inside the mass-spectrometer source in vacuum and in the solid phase of a crystal grown at high ionic strength.

\subsection{The change in the protein polyelectrolyte with increasing ionic strength}

When isoionic HEWL is brought to $\mathrm{pH} 4.5$ it acquires a net charge of about +10 and has at least ten counter-ions. Its solubility with $\mathrm{Cl}^{-}$as counter-ion is as high as $366 \mathrm{mg} \mathrm{ml}^{-1}$ (Retailleau, Riès-Kautt et al., 1997). Increasing the salt concentration not only affects the hydration of the protein polyelectrolyte in solution but also changes its composition, since ions bind to specific sites of the protein. Along the phase diagram different HEWL complexes are formed because of the binding of an increasing number of counter-ions and coions, with their amount depending on their nature and on their own affinity towards the different types of protein binding sites. The overall net charge of the complex is therefore affected, as is its solubility.

The behaviour of a protein in solution can consequently no longer be considered only in terms of a given polyelectrolyte with its net charge and hydration shell, but has to be addressed at the atomic level of local competition of solvent molecules and ions, i.e. the contribution of the chemistry of the salt effect in protein crystallization in terms of favourable ion pairs of soft ions with soft protein sites or hard ions with hard protein sites according to the law of matching water affinity (Collins, 2012). Since soluble proteins expose the same amino acids to the solvent, the HEWL results on ion-protein interactions can be transposed to general rules for the crystallization of soluble proteins, as well as to their folding and stability.

Francine Libot is acknowledged for initial ESI-MS analysis of dissolved crystals in acetonitrile/water. PB was supported by the European Biocrystallogenesis initiative (contract No. BIO4-CT98-0086 (DG12-SSMI). We thank the Centre National de la Recherche Scientifique (CNRS) for financial support of this project. We acknowledge the Laboratoire pour l'Utilisation du Rayonnement Electromagnétique (LURE) and the European Synchrotron Radiation Facility (ESRF) for providing the synchrotron-radiation facilities, and particularly Dr C. Mueller-Dieckmann for assistance in using beamline ID29 at the ESRF. The authors are indebted to Professor T. Prangé, Professor C. W. Carter and Professor A. Ducruix for helpful scientific discussions.

\section{References}

Angel, L. A. (2011). Eur. J. Mass Spectrom. 17, 207-215.

Arakawa, T. \& Timasheff, S. N. (1984). Biochemistry, 23, 5912-5923.

Bénas, P., Legrand, L. \& Riès-Kautt, M. (2002). Acta Cryst. D58, 1582-1587.

Brünger, A. T., Adams, P. D., Clore, G. M., DeLano, W. L., Gros, P., Grosse-Kunstleve, R. W., Jiang, J.-S., Kuszewski, J., Nilges, M., Pannu, N. S., Read, R. J., Rice, L. M., Simonson, T. \& Warren, G. L. (1998). Acta Cryst. D54, 905-921.

Collins, K. D. (2004). Methods, 34, 300-311.

Collins, K. D. (2006). Biophys. Chem. 119, 271-281.

Collins, K. D. (2012). Biophys. Chem. 167, 43-59.

Collins, K. D. \& Washabaugh, M. W. (1985). Q. Rev. Biophys. 18, 323-422.

Dauter, Z. \& Dauter, M. (1999). J. Mol. Biol. 289, 93-101.

Dauter, Z., Dauter, M., de La Fortelle, E., Bricogne, G. \& Sheldrick, G. M. (1999). J. Mol. Biol. 289, 83-92.

Emsley, P., Lohkamp, B., Scott, W. G. \& Cowtan, K. (2010). Acta Cryst. D66, 486-501.

French, S. \& Wilson, K. (1978). Acta Cryst. A34, 517-525.

Hamiaux, C., Prangé, T., Riès-Kautt, M., Ducruix, A., Lafont, S., Astier, J. P. \& Veesler, S. (1999). Acta Cryst. D55, 103-113.

Heck, A. J. \& Van Den Heuvel, R. H. (2004). Mass Spectrom. Rev. 23, 368-389.

Hippel, H. von \& Schleich, T. (1969). Structure Stability of Biological Macromolecules, edited by F. E. Timasheff, pp. 418-574. New York: Marcel Dekker.

Hofmeister, F. (1888). Arch. Exp. Pathol. Pharmakol. 24, 247-260.

Jones, T. A., Zou, J.-Y., Cowan, S. W. \& Kjeldgaard, M. (1991). Acta Cryst. A47, 110-119. 
Joosten, R. P., Joosten, K., Cohen, S. X., Vriend, G. \& Perrakis, A. (2011). Bioinformatics, 27, 3392-3398.

Kabsch, W. (2010a). Acta Cryst. D66, 125-132.

Kabsch, W. (2010b). Acta Cryst. D66, 133-144.

Kunz, W., Henle, J. \& Ninham, B. W. (2004). Curr. Opin. Colloid Interface Sci. 9, 19-37.

Lemaire, D., Marie, G., Serani, L. \& Laprévote, O. (2001). Anal. Chem. 73, 1699-1706.

Li, S. J., Matsuura, T., Tanaka, H., Nakagawa, A., Tsukihara, T. \& Ataka, M. (2005). J. Cryst. Growth, 276, 222-229.

Mao, D., Babu, K. R., Chen, Y.-L. \& Douglas, D. J. (2003). Anal. Chem. 75, 1325-1330.

McCoy, A. J., Grosse-Kunstleve, R. W., Adams, P. D., Winn, M. D., Storoni, L. C. \& Read, R. J. (2007). J. Appl. Cryst. 40, 658-674.

Ménez, R. \& Ducruix, A. (1990). J. Mol. Biol. 216, 233-234.

Ménez, R. \& Ducruix, A. (1993). J. Mol. Biol. 232, 997-998.

Moreau, S., Awadé, A. C., Mollé, D., Le Graet, Y. \& Brulé, G. (1995). J. Agric. Food Chem. 43, 883-889.

Navaza, J. (1994). Acta Cryst. A50, 157-163.

Otwinowski, Z. \& Minor, W. (1997). Methods Enzymol. 276, 307-326.

Pearson, R. G. (1987). J. Chem. Educ. 64, 561.

Potier, N., Rogniaux, H., Chevreux, G. \& Van Dorsselaer, A. (2005). Methods Enzymol. 402, 361-389.

Pramanik, B. N., Bartner, P. L., Mirza, U. A., Liu, Y.-H. \& Ganguly, A. K. (1998). J. Mass Spectrom. 33, 911-920.

Read, R. J. (1986). Acta Cryst. A42, 140-149.

Retailleau, P., Ducruix, A. \& Riès-Kautt, M. (2002). Acta Cryst. D58, 1576-1581.

Retailleau, P., Riès-Kautt, M. \& Ducruix, A. (1997). Biophys. J. 73, 2156-2163.

Riès-Kautt, M. M. \& Ducruix, A. F. (1989). J. Biol. Chem. 264, 745-748.
Riès-Kautt, M. M. \& Ducruix, A. F. (1991). J. Cryst. Growth, 110, $20-25$.

Riès-Kautt, M. \& Ducruix, A. (1997). Method Enzymol. 276, 23-59.

Riès-Kautt, M., Ducruix, A. \& Van Dorsselaer, A. (1994). Acta Cryst. D50, 366-369.

Saludjian, P., Prangé, T., Navaza, J., Ménez, R., Guilloteau, J. P., RièsKautt, M. \& Ducruix, A. (1992). Acta Cryst. B48, 520-531.

Tanford, C. (1961). Physical Chemistry of Macromolecules, pp. 238253. New York: John Wiley \& Sons.

Tanford, C. \& Wagner, M. L. (1954). J. Am. Chem. Soc. 76, 33313336.

Thomas, B. R., Vekilov, P. G. \& Rosenberger, F. (1996). Acta Cryst. D52, 776-784.

Vaney, M. C., Broutin, I., Retailleau, P., Douangamath, A., Lafont, S., Hamiaux, C., Prangé, T., Ducruix, A. \& Riès-Kautt, M. (2001). Acta Cryst. D57, 929-940.

Vaney, M. C., Maignan, C., Riès-Kautt, M. \& Ducruix, A. (1996). Acta Cryst. D52, 505-517.

Vocadlo, D. J., Davies, G. J., Laine, R. \& Withers, S. G. (2001). Nature (London), 412, 835-838.

Washabaugh, M. W. \& Collins, K. D. (1986). J. Biol. Chem. 261, 12477-12485.

Weiss, M. S., Panjikar, S., Nowak, E. \& Tucker, P. A. (2002). Acta Cryst. D58, 1407-1412.

Whittal, R. M., Ball, H. L., Cohen, F. E., Burlingame, A. L., Prusiner, S. B. \& Baldwin, M. A. (2000). Protein Sci. 9, 332-343.

Winn, M. D. et al. (2011). Acta Cryst. D67, 235-242.

Winston, R. L. \& Fitzgerald, M. C. (1997). Mass Spectrom. Rev. 16, 165-179.

Zhang, Y. \& Cremer, P. S. (2006). Curr. Opin. Chem. Biol. 10, 658-663. 